\title{
Hercules Romanus, Hercules Gaditanus, Iovis OLYMPIUS, SANDAN Y IUPITER VICTOR: CULTOS LOCALES Y SELECCIONES IMPERIALES EN LA MONEDA DE ADRIANO
}

Hercules romanus, Hercules gaditanus, IOVIS Olympius, SANDAN AND IUPITER VICTOR: LOCAL CULTS AND IMPERIAL SELECTIONS ON HADRIAN'S COINAGE

FERNANdo López SÁNCHez

Universidad COMplutense de Madrid / WOLFSON COllege, OXford FLOPEZSANCHEZ@HOTMAIL.COM

\section{RESUMEN}

La viajera biografía del emperador Adriano se suele agrupar en dos grandes giras. La primera se realizó entre los años 121 y 126 y concernió principalmente a Occidente. La segunda se hizo principalmente por Oriente $\mathrm{y}$ afectó fundamentalmente a algunas de las principales ciudades de Asia Menor, Capadocia, Siria, Judea y Egipto. En medio de su primera gran gira, Adriano, en el año 124, se inició en Eleusis, en las cercanías de Atenas, y en asociación con Hércules. Al principio de la segunda gira, en el año 128 y tras visitar África, el emperador participó en otros ritos mistéricos en Eleusis, vinculándose a partir de entonces a Zeus Olympius en Atenas. En este artículo, se ofrece una nueva lectura de la trayectoria gubernativa de Adriano a través de algunas de sus más significativas series

\begin{abstract}
The emperor Hadrian's travel biography is generally divided into two major phases. The first, mostly in the West, took place between the years 121 and 126, while the second was centred on the East, in particular in some of the key cities of Asia Minor, Cappadocia, Syria, Judaea and Egypt. During the first phase, in the year 124, Hadrian was initiated at Eleusis, near Athens, following in the tradition of Hercules. After his visit to Africa at the start of the second phase of his travels in 128, he took part in further mystic Eleusinian rites, this time linking him to Zeus Olympius in Athens. Looking at some of his most important coin series, both imperial and civic, this article provides a new interpretation of Hadrian's career as governor, suggesting that there was a dual-
\end{abstract}


monetales, imperiales y cívicas. Se defiende que Adriano siguió un doble modelo organizativo a lo largo de su reinado, sucesivamente hercúleo y jupiterino. Tal modelo fue conceptualmente macedonio, pero tuvo ecos y paralelos en otros emperadores, poseyendo plena vigencia hasta los tiempos de Diocleciano y Maximiano. ity to the years of the emperor's rule, as he first modelled himself on Hercules and then on Jupiter. This was a Macedonian concept, but there are echoes and parallels to be found with other emperors, culminating in Diocletian and Maximian.

\section{KEY WORDS}

Flota, Hércules, iniciación, Júpiter, moneda, montaña, templo, viaje, visita

\section{KeYWORDS}

Coin, fleet, Hercules, initiation, Iupiter, mountain, temple, travel, visit 


\section{Las dos giras viajeras de Adriano y el modelo de gobierno HERCÚLEO-JUPITERINO}

Entre los años 117 y 134, ${ }^{1}$ el emperador Adriano recorrió buena parte del imperio romano, visitando y reconociendo muchas ciudades y provincias. ${ }^{2}$ Sus viajes se pueden dividir en dos fases principales. La primera comenzó a partir del año 121, tras llegar a Roma desde Antioquía y habiendo recorrido anteriormente Cilicia, Galacia y buena parte del valle del Danubio. ${ }^{3}$ Entonces decidió apuntalar las fronteras del norte de Roma, conociendo de esta manera de primera mano las provincias de la Galia y de la Germania Inferior y Superior. El emperador cruzó luego el Canal de la Mancha hacia Britania, donde comenzó entonces la construcción del conocido hoy en día como "muro de Adriano". En los años 122-123, pasó un tiempo en Hispania y probablemente también en Mauritania, viajando después por Libia, Cirene, Siria, la frontera del Eúfrates (Melitene) el Ponto y Bitinia. El resto de esta primera gira la dedicó finalmente a los Balcanes y a Grecia, recorriendo áreas como Tracia, Dacia y Acaya, antes de regresar a Roma, vía Sicilia, en el año 126. ${ }^{4}$ Durante este primer ciclo viajero, Adriano se ocupó en rediseñar y mejorar las fronteras del imperio de Occidente: con fortificaciones que completó a lo largo del Rin, con una zanja que cavó en el norte de África (fossatum Africae), con un muro de empalizada que erigió contra Partia y con el famoso muro en Gran Bretaña que “dividió a los bárbaros

1. Todos los años son d.C., salvo aquellos en los que se indique lo contrario.

2. Halfmann, 1986, pp. 188-212.

3. Birley, 2004b, pp. 107-126.

4. Birley, 2004b, pp. 153-247. 
de los romanos". ${ }^{5}$ Adriano había decidido abandonar las conquistas de Trajano al poco tiempo de ser aclamado emperador y parece como si, de acuerdo con un pensamiento a un tiempo mágico y militar, hubiese tenido la intención de extender en su primera gira provincial el pomoerium de la ciudad de Roma a todo el orbe romano. ${ }^{6}$ Puede afirmarse en todo caso que existieron profundas consideraciones religiosas en esta primera gira organizativa de Adriano, además de las obvias de carácter estratégico. Es algo que confirma también el biógrafo de la Vita Hadriani cuando afirma que al finalizar su primer tour de viajes, y durante su primera visita a Grecia en el año 124, Adriano "realizó los ritos eleusinos de Eleusis siguiendo el ejemplo de Hércules y Filipo (II de Macedonia)".

El segundo gran tour que realizó Adriano por el imperio comenzó en septiembre del año 128. Emprendió primero un breve circuito por África, pero regresó al poco a Roma, y tras una breve estancia en la ciudad, se dedicó a partir del año 130 a recorrer la parte más helénica y oriental del imperio. Visitó de nuevo Asia Menor, pero también Panfilia, Frigia, Pisidia, Capadocia, el Ponto, posiblemente Cilicia y con seguridad Siria (Antioquía). Luego se acercó a Judea, personándose en Cesarea y quizás en Escitópolis, en Jerusalén, (que rebautizó como Aelia Capitolina), en Arabia Petrea y finalmente en Egipto. La revuelta en Judea de Shim’on ben Koseba, más conocido como Bar-Kochba, le obligó no obstante a permanecer en la región hasta el año 134. Sólo a finales de este año 134 regresó Adriano a Italia, poniendo definitivamente punto final a sus largos viajes. ${ }^{8}$ Antes de emprender este segundo gran itinerario, sin embargo, el emperador participó de nuevo en otros misterios de Eleusis, cerca de Atenas. En esta ocasión su protegido Antinóo debió haber estado con él, aunque ciertamente ninguna fuente atestigua su presencia con total seguridad. La evidencia

5. HA, Had. 11, 2; Birley, 2004b, pp. 156-157, 176-179, 269-270.

6. Adriano representa frecuentemente a Minerva en sus amonedaciones y esta prelidección no es fruto del azar, sino reflejo de un imperio romano con unas fronteras que se quieren definitivamente establecidas. Tanto Domiciano como Adriano, ambos devotos de Minerva, pueden haber compartido una vision similar del imperio, a pesar de sus carreras diferenciadas. En todo caso, ni Domiciano ni Adriano extendieron un pomoerium que sí que fue modificado en el siglo I d.C. en concomitancia con las actividades militares en Britannia. Es el caso de la extensión del año 49, como consecuencia de los éxitos britanos de Q. Petilius Cerialis y del año 75, cuando se agrandó hasta el Collis Hortulorum, al norte de la ciudad y ya en la llanura aluvial del Tiber; Levick, 1999, pp. 71, 130, n. 20 y López Sánchez, 2007.

7. HA, Had. 13, 1; Cass. Dio, LXIX 11, 1; Birley, 2004b, p. 229.

8. Birley, 2004b, pp. 276-353.

ARYS, 16, 2018 [63-103] ISSN 1575-166x 
posterior que parece asociar a Antinóo con Eleusis hace plausible no obstante que éste realizara los ritos con el emperador en septiembre del año $128 .^{9}$

En su conexión con Ceres y con la muerte, los ritos de Eleusis servían para honrar la memoria de distintos miembros de la familia imperial, sobre todo femeninos. Adriano pudo de hecho haber aprovechado cada una de sus celebraciones como sacerdote eleusino para honrar la memoria de sus antepasados e iniciar en ellas a nuevos miembros, como fue el probable caso de Antinóo ya mencionado. ${ }^{10}$ En todo caso, Adriano ya no fue de la mano de Hércules en Atenas en septiembre del año 128, sino de la de Júpiter. ${ }^{11}$ El emperador, asimilado con insistencia desde entonces al árbitro supremo del cosmos ya no se preocupó de asegurar como antaño, y con prioridad, las fronteras externas del Imperio. ${ }^{12} \mathrm{Al}$ contrario, a partir de entonces pretendió reinar y ser reconocido como soberano indiscutido sobre el oikoumene civilizado, esto es, sobre el Este más helenófono del Imperio. Adriano parece haber salido así de sus ritos en Eleusis del año 128 listo para desarrollar un plan de gobierno en Oriente mucho más ambicioso que aquel que había llevado a cabo años atrás en Occidente. Ahora crearía un Panhelenio, esto es, una asociación de todos los helenos y con Atenas como centro. ${ }^{13} \mathrm{Y}$ construiría también un templo para Hera y otro para Zeus Panhelenios, además de un santuario (Panteón) para todos los dioses del Olimpo. ${ }^{14} \mathrm{De}$ esta manera, acompañado por su Ganímedes particular, el efebo Antinóo, ${ }^{15}$ el ahora majestuoso y jupiterino Adriano consagró entre los años 129 y 132 varios templos a su nombre y al de Júpiter. Y concedió también diversos privilegios a numerosas ciudades, celebrándose en ellas numerosos juegos. Estas prácticas eran en lo fundamental ciertamente extranjeras a la Grecia continental, pero poseían una larga tradición tanto en Asia Menor como en la franja siro-palestina, encontrándose a gusto Adriano con todas ellas. Los movimientos del emperador en estos años parecen además haber querido revivir un helenismo arcaizante y anti-persa, muy del gusto de su predecesor modelo en la región, Alejandro Magno. ${ }^{16}$

9. Birley, 2004b, pp. 276 y n. 1, 435.

10. Probablemente para vincular al mayor número de miembros de la familia imperial con estos ritos, Spaeth, 1996, p. 27; Aur. Vict., Caes. 14 dice que Adriano introdujo en Roma la iniciación de Ceres y Libera en su vertiente eleusina.

11. Birley, 2004b, pp. 281-282.

12. Hekster, 2005, p. 208 llama "untraditional" a Adriano por ésta y por otras razones. Ver supra.

13. Gordillo Hervás, 2012, pp. 37-43.

14. Birley, 2004b, p. 281.

15. Birley, 2004b, pp. 276-277; Williams, 2010, pp. 60-61.

16. Birley, 2004b, p. 282. 
A. Birley señala en relación con todo este modelo ideológico hasta aquí esbozado que no está nada claro por qué el biógrafo de la Historia Augusta insiste tanto en los precedentes de Hércules y Filipo II de Macedonia durante los primeros ritos eleusinos de Adriano como emperador. ${ }^{17}$ Se han sugerido a este respecto correcciones a este pasaje concreto de la HA, considerándose por algunos como corrupto. ${ }^{18}$ De hecho para A. Birley Hércules fue una cosa, estando su parte en la leyenda de los misterios eleusinos bien establecida y Filipo de Macedonia, el enemigo de Atenas, otra muy distinta. ${ }^{19}$ Sin embargo, y a pesar de las dudas existentes acerca de la completa autenticidad de este fundamental texto, lo cierto es que sí que existió un deseo de emulación por parte de Adriano con respecto a la casa real macedonia de Filipo II y Alejandro III. Y derivado de este deseo puede reconstruirse un recorrido de gobierno para este emperador que parece que fue en su conjunto hercúleo-jupiterino. Así, y por esta razón precisamente, los dos más fundamentales ritos eleusinos en la vida de Adriano, los de los años 124 y $128^{20}$ se quisieron jalones fundamentales en la orientación ideológica de su reinado. Sin embargo, como su recorrido ideológico no fue nuevo, sino inspirado por los ejemplos vitales de Filipo II y Alejandro III, merece la pena examinar primero la trayectoria de estos últimos.

\section{El MODELO DE GOBIERNO HERCÚLEO-JUPITERINO MACEDONIO: EL INCOMPLETO DE FILIPO II Y EL CUASI-COMPLETO AlEJANDRO III}

Ciertamente, hay razones para pensar que Alejandro III consideró a Dioniso como a su deidad tutelar en la conquista de Asia y de Oriente. ${ }^{21}$ No obstante, los dioses tutelares del reino de Macedonia habían sido desde antiguo Zeus, Atenea y Herakles. Herakles se había constituido desde el siglo V a.C. en el patrón de la dinastía argéada a través del argivo Témeno, ${ }^{22}$ mientras que Atenea se había elegido como diosa protectora de la capital Pella y por extensión de todo el hogar patrio. Por su parte, Zeus se había erigido en soberano y árbitro - basileos - de todos los dioses, estando muy vinculado con el territorio de Macedonia, como también con el de toda Grecia.

17. La vinculación de Adriano con los misterios de Eleusis pudo haber comenzado antes, posiblemente cuando fue arconte de Atenas, tal y como lo sugiere Clinton, 1989 y 1997. La importancia de los ritos del año 124, sin embargo, radica en que son los primeros realizados en tanto que emperador.

18. Oliver, 1950; Birley, 1997; Brennan, 1998.

19. HA, Had. 13, 1; Birley, 2004b, pp. 230-231 y n. 2, 428.

20. Además de una posible participación en unos primeros ritos eleusinos en tanto que arconte de Atenas o poco después vid. n. 17, también participó en otoño del año 131 en otros, Birley, 2004b, p. 334.

21. Fredricksmeyer, 2000, p. 144.

22. Hdt., VIII 137-139.

ARYS, 16, 2018 [63-103] ISSN 1575-166X 
No puede resultar extraño de esta manera que, gobernando Filipo II como caudillo militar sobre la Hélade (hēgemōn), adoptase el busto del árbitro Zeus para sus tetradacmas, las unidades de plata más importantes y prestigiosas de su reino (Fig. 1). A Herakles lo reservó por su parte a los subdivisores de dos dracmas (Fig. 2) ${ }^{23}$ estructurando así sus emisiones monetales en torno a un eje jerárquico muy claro en el que Zeus (el más poderoso de los dioses) gobernaba sobre Herakles (el mejor de todos los hombres). El guiño a Zeus en las acuñaciones macedonias también se extendió al oro, pues en las estáteras de Filipo se hizo representar a éste rey como ganador de la carrera de bigas en Olimpia del año 348 a.C. ${ }^{24}$

Tras el asesinato de Filipo II, se continuaron dedicando a Herakles, Zeus y Athena el grueso de las series monetales dichas "imperiales" de Alejandro III. Esto se hizo así probablemente ya antes de la marcha hacia Asia del año 334 y en todo caso no después de los años 333/332 a.C. ${ }^{25}$ El aún muy joven Alejandro adoptó en todo caso en Tarso en el año 333 a.C. a Herakles como protector personal, probablemente tanto en razón de su fragilidad en el trono, cuanto por su condición de batallador contra el Gran Rey persa. Finalmente, y como Filipo antes que él, Alejandro adoptó igualmente un tipo propagandístico para su campaña panhelénica contra Persia (ca. 335/334 a.C.): un busto de Atenea, diosa principal del centro cultural del mundo griego (Atenas), con casco corintio. Alejandro, además de rey de Macedonia, respetaba la herencia de Filipo II y se constituía él también en hēgemōn de la Liga de Corinto (Figs. 1-2). ${ }^{26}$

Sin suplantar nunca a Herakles, Zeus se abrió no obstante paso con fuerza en la ideología aúlica del nuevo rey macedonio. Se identifica Alejandro con él en tanto que gobernante de toda Asia, ${ }^{27}$ tanto en el anuncio de Gordium (333 a.C.) ${ }^{28}$ como en la confirmación de Siwa en el santuario de Zeus-Amón (331 a.C.). ${ }^{29}$ Así, y en los reversos de las monedas de plata alejandrinas que honran a Herakles, se adoptó tempranamente la imagen de un Baal-Zeus entronizado y aetophoros (sostenedor del

23. Thonemann, 2015, p. 10.

24. El lugar era presidido y protegido por el árbitro del Olimpo, Plut., Alex. 4, 9; Thonemann, 2015, p. 9.

25. Price, 1991, pp. 27-29 para la cronología antigua de estas emisiones y pp. 29-31 para los espacios diferenciados de cada una de estas divinidades en relación con las empresas de Alejandro. Otros comentarios en Fredricksmeyer, 2000, p. 144.

26. Thonemann, 2015, p. 11.

27. Arr., II 3, 2-8.

28. Fredricksmeyer, 1961, pp. 160-168.

29. Fredrricksmeyer, 1991, pp. 199-214. 
águila). ${ }^{30}$ Alejandro elegía al hacer así una imagen que conllevaba diferentes connotaciones simbólicas para dos audiencias distintas: la continuidad con el dominio persa para sus nuevos súbditos en Cilicia y Fenicia a través de un Bảal adorado por el sátrapa persa Mazaeus y la tradicional piedad helénica con Zeus para su ejército macedonio (Fig. 3). A los pocos años, sin embargo, tras conquistar definitivamente todo el imperio aqueménida y poco antes de su muerte (324 a.C.), Alejandro comenzó también a asociar el título de $\mathrm{BA} \Sigma \mathrm{I} \Lambda \mathrm{E} \Omega \Sigma$ a su nombre en el reverso. Basileos suele ser un vocablo usualmente traducido como "rey", pero en estas emisiones monetales poseía las connotaciones de "supremo" o "árbitro", atributos ambos atribuidos tradicionalmente a Zeus. El apelativo de basileos comenzó así a utilizarse en Babilonia, en el levante siro-palestino, en Asia Menor y en Macedonia ${ }^{31}$ en relación con quien ahora se consideraba a sí mismo como árbitro del oikumene (Fig. 4).

Y es que, tal y como le había escrito en el año 338 a.C. Isócrates a Filipo II, tras la conquista del imperio persa no le quedaba al putativo conquistador sino convertirse en un dios. ${ }^{32}$ De hecho, y en relación con este consejo o predicción, años después Alejandro pidió a los estados griegos que establecieran cultos no sólo en honor de su difunto amigo Hefesteion en tanto que "héroe", sino también en su honor propio y con el rango de dios. Esgrimió Alejandro que había sido un benefactor excepcional del mundo griego y ya en el año 323 a.C., antes de su muerte, se rindió culto al monarca macedonio en altares ${ }^{33} y$ por medio de estatuas y celebraciones de juegos. ${ }^{34}$ Asimismo, varias embajadas venidas de Grecia comenzaron también a saludar a Alejandro en tanto que a una divinidad, coronándosele con coronas de oro. ${ }^{35}$

Es probable que Alejandro hubiese seguido ascendiendo en la estructuración divina potenciada por Filipo de haber vivido más y de haber podido organizar mejor su extenso imperio. Esto es, que se hubiese encomendado más a Zeus en tanto que rector de su nuevo imperio, dejando más de lado a Herakles. ${ }^{36}$ En cualquier caso, y aunque fuese al final de su vida, Alejandro sí que parece haber completado todo un programa ideológico esbozado en tiempos de Filipo, aunque Filipo no hubiese tenido tiempo de desarrollarlo. Tal programa, muy simple, no era sino el de la organización

30. Troxell, 1997, pp. 87-89; Casabonne, 2004, pp. 207-236.

31. Price, 1991, pp. 32-33.

32. Isoc., Ep. 3, 5; Flower, 2000, p. 121.

33. En Atenas, Hyp. I 31, 6, 21.

34. Por los jonios, Str., 644.

35. Estando Alejandro en Babilonia, Arr., VII 23, 2; ver Hammond y Walbank, 2003, p. 87 y nn. 17 y 18. 36. Price, 1991, p. 31. 
del oikumene gracias a hercúleos esfuerzos militares primero y mediante una administración arbitral y burocrática después.

\section{EL MODELO DE GOBIERNO HERCÚLEO-JUPITERINO ROMANO: NO SÓLO Maximiano y Diocleciano, también Adriano}

El impacto que el modelo hercúleo-jupiterino de gobierno tuvo entre los sucesores de Alejandro Magno fue enorme. ${ }^{37} \mathrm{Y}$ también influyó grandemente en buen número de emperadores romanos. La lógica complementaria de este modelo ideológico desembocó así, y de forma natural, en la estructura marcadamente castrense de las tetrarquías, que no hizo sino sistematizar presupuestos ya asumidos por varios de los colegios imperiales anteriores. ${ }^{38}$ De esta manera, tanto los dos panegíricos latinos entregados en la corte de Maximiano en Tréveris en los años 289 y 291, ${ }^{39}$ cuanto el grueso de las acuñaciones de la ceca de Lyon durante este período, reflejan una ideología de poder modelada a partir de la solidaridad hercúleo-jupiterina de Maximiano con Diocleciano. Ambos medios, panegíricos y series monetales, enfatizan la entente gubernativa existente entre el Hércules pacator terrarum de Maximiano y el Júpiter rector caeli de Diocleciano. ${ }^{40}$ Los cognomina Herculius y Iovius ${ }^{41}$ se adoptaron también por entonces y con su significación adjetival "de Hércules" y "de Júpiter" 42 significando el plural AVGG añadido a muchas de las monedas de ambos soberanos que cada protector tutelar también servía a su colega.

37. Dahmen, 2007, pp. 58-64. La confusión entre el busto de Alejandro y el de Herakles fue frecuentemente intencionada en las series monetales helenísticas (Dahmen, 2007, pp. 39-41), aunque siempre se privilegió a Herakles sobre el soberano macedonio, que no llego a representar su busto en vida. La acumulación de atributos (Dahmen, 2007, p. 42) en un busto herácleo, con los cuernos de Amón y a la vez personalizado, no fueron sin embargo totalmente excepcionales. Este es el caso de Lisímaco, por ejemplo (Dahmen, 2007, pp. 48-50).

38. La tipología hercúleo-jupiterina desaparece sin embargo en las acuñaciones de la primera tetrarquía (294-305) con la adopción de las genéricas emisiones GENIO POPULI ROMANI, no recuperándose tampoco con la segunda tetrarquía (305-313). Ver San Vicente, 2002. Sin embargo, posteriormente al año 284, y con anterioridad al año 294, esta riqueza programática es muy visible; Bastien, 1972 continúa siendo la obra de referencia para las adscripciones hercúleas y jupiterinas de los primeros años de gobierno de Diocleciano y Maximiano; Ver también Abdy, Besly y López-Sánchez, 2010, pp. 29-30 y pp. 98-109. Rees, 2005 y López Sánchez, 2006 para otros casos de finales del siglo III en la Galia.

39. Pan. I [2] y Pan. II [3].

40. Steinbock, 2014, pp. 51-55; Bastien, 1972.

41. Rees, 2002, p. 32 las llama signa.

42. Nixon y Rodgers, 1994, pp. 44. 
Sin embargo, y a pesar de que Júpiter y Hércules funcionaron como protectores de los dos emperadores a la vez, ${ }^{43}$ Diocleciano y Maximiano se consideraron en todo momento como fundamentalmente diferentes. El gobernante majestuoso fue siempre Diocleciano, reinando sobre Oriente con la ayuda de Júpiter. Su ayudante, esto es, aquel que había liberado a la tierra de los principales peligros que la acechaban en los frentes germano, britano, galo e hispano y que sólo gobernaba gracias a haber desplegado un gran esfuerzo guerrero, fue sólo Maximiano. ${ }^{44}$ Esta dualidad hercúleo-jupiterina creada poco después del año 284, e institucionalizada en la llamada primera tetrarquía tras el año 294, fue conformada posiblemente para reflejar el poder diferencial de un Diocleciano superior sobre un Maximiano subordinado. ${ }^{45}$ De hecho, el panegirista Mamertinus identifica que la legitimidad última de Maximiano derivaba únicamente de su designación por Diocleciano. ${ }^{46}$ Por tanto, y de la misma manera en como Hércules había sido enviado por Júpiter al mundo para desempeñar ciertas labores en la tierra, así Maximiano había sido también encargado de limpiar Occidente de enemigos por parte de Diocleciano. De esta manera, y de forma lógica, Diocleciano siempre se reservó para sí Oriente, poseyendo desde el principio más prestigio que Maximiano. Su imperio no fue el occidental de Hércules, sino el más civilizado y oriental de Zeus Olympius. ${ }^{47}$

La fuerza del modelo hercúleo-jupiterino en el mundo grecorromano no se circunscribió sin embargo a Maximiano y Diocleciano. Otros emperadores romanos lo adoptaron, no siendo ni herederos estrictos del helenismo post-alejandrino ni tampoco prefiguraciones de las tetrarquías tardorromanas. En el caso de Adriano, a falta de fuentes textuales de la calidad y la extensión de los Panegíricos Latinos, son sus series monetales las únicas que pueden proporcionar una idea cabal de hasta qué punto este emperador se identificó con los criterios de poder hercúleo-jupiterinos de cuño macedonio. Si según A. Wallace-Hadrill, los tipos representados en las series monetales greco-romanas, tanto en el anverso como en el reverso, estaban "cargados de valores", eran "persuasivos" y representaban "imágenes de autoridad", 48 entonces pueden ser leídos como documentos áulicos de poder plenamente fiables. Puesto que además se admite que Trajano intervino personalmente en las actividades de la ceca de Roma, eligiendo los tipos monetales deseados para "contarle a Roma y al mundo

43. Kuhoff, 2001, p. 41.

44. RIC VI, p. 8.

45. Kuhoff, 2001, p. 41.

46.Pan. 10 [2] 3.1, 4.1.

47. Rees, 2002, p. 47; Steinbock, 2014, p. 56.

48. Wallace-Hadrill, 1986, p. 69. 
lo que esperaba, lo que había planeado y lo que había logrado”, ${ }^{49}$ puede suponerse que algo similar sucedió con su sucesor Adriano.

Si esto sucedió así en el caso concreto de la ceca de Roma, lo mismo puede asumirse para las grandes cecas provinciales. Se sabe precisamente a este respecto, y desde hace algunos años, que las actividades de algunas de las principales cecas cívicas de Oriente en tiempos de Trajano y Adriano, entre las cuales se cuentan Alejandría, Antioquía y otras, coordinaron sus esfuerzos de forma sistemática, recibiendo instrucciones, grabadores o incluso monedas fabricadas de parte de la ceca de Roma. ${ }^{50}$ Puede realizarse de esta manera una aproximación completa y fiable a la ideología imperial de Adriano a través del estudio de varias de sus series monetales, y a pesar de no contar el historiador moderno con testimonios textuales sobre el particular. De entre las numerosas series monetales susceptibles de ser estudiadas este artículo se centra no obstante en aquellas que representan a Hercules Romanus, a Hercules Gaditanus, a Iovis Olympius, a Sandan y a Iupiter Victor. Algunas de estas emisiones hacen referencia a cultos locales (Hercules Romanus, Hercules Gaditanus, Sandan) mientras que otras se dedican a divinidades panhelenias o imperiales (Iovis Olympius, Iupiter Victor). Todas se encuentran sin embargo conectadas entre sí, pues parecen haber sido consecuencia de unas selecciones imperiales muy cuidadas. De su comprensión depende en todo caso el entendimiento del programa ideológico hercúleo-jupiterino de Adriano.

\section{HERCULES RomANUS: POMOERIUM INTERNO Y FRONTERAS EXTERNAS}

Cuando Trajano murió en Cilicia en agosto del año 117, la transición del poder imperial no fue tan crítica como en el año 69, pero sí más peligrosa que en el año $97 .^{51}$ La adopción del heredero Adriano había sido planeada por un hombre agonizante y estuvo en todo momento gestionada por la emperatriz Plotina. Sin embargo, a pesar de ello, o precisamente por ello, los honores votados por el senado en honor de Trajano a fines de septiembre del año 117 fueron más allá de la propia propuesta del

49. BMC III, p. clxxi.

50. Butcher, 2004, pp. 248-250; Burnett, 2005, pp. 271-274; RPC II, p. 10.

51. Birley, 2004b, p. 107; Ver también Bennett, 2001, pp. 40-62 para el intento de Nerva de evitar los sucesos de los años 68-69 y Alföldy y Halfmann, 1973 para la gravedad de la crisis sucesoria y la posibilidad real de la repetición de una temida guerra civil; Alston, 2014, p. 262 para las dos versiones sobre la naturaleza del acceso al poder de Trajano y sobre el posible coup que pudo haber significado la instauración de Trajano en la púrpura. 
nuevo emperador. Según el senado, Adriano debería celebrar un triunfo en Roma, ${ }^{52}$ otorgándosele además el título de Pater Patriae. También se emitieron monedas en Roma a finales del año 117, una de ellas con el busto del difunto Trajano como emperador en el anverso y con el de Adriano en el reverso, rodeado este último de la leyenda HADRIANUS TRAIANUS CAESAR. Otra serie monetal, acuñada también poco después de la muerte de Trajano, muestra a Adriano como emperador con el nombre de TRAIANUS HADRIANUS y con los títulos de Trajano de OPTIMUS AUGUSTUS GERMANICUS DACICUS. En el exergo del reverso puede leerse igualmente la leyenda ADOPTIO, con Trajano y Adriano estrechándose las manos (dextrarum iunctio) y Trajano reflejando el título de PATER PATRIAE, además de otros. ${ }^{53}$ La necesidad de proclamar la legitimidad de la sucesión imperial en Roma por parte del senado queda así patente en la ceca de Roma. Este mismo taller anunció además durante los meses finales del año 117 y gran parte del año 118, y a través de la leyenda FORT(UNA) RED(UX)(“Feliz Regreso"), que se esperaba ansiosamente en Roma la llegada del nuevo emperador. ${ }^{54}$

Si bien la disposición del senado de Roma hacia Adriano parece haber sido entusiasta, a tenor de lo anteriormente expuesto, el heredero de Trajano sabía muy bien que su situación era muy precaria, ya que tenía numerosos enemigos, tanto en la capital como en otros lugares. De esta manera y pocos días después de la muerte de su predecesor, Adriano dio la orden de evacuación total de Mesopotamia, de Asiria y de la Gran Armenia. ${ }^{55}$ Como consecuencia de esta orden, el reinado de Adriano conoció una caída espectacular en la producción de moneda en todo el norte de Siria: ${ }^{56}$ la acuñación de tetradracmas cesó muy pronto en la región a principios del tercer consulado de Adriano y el uso de una larga y muy completa leyenda de anverso en sus emisiones antioquenas, en lugar de la posterior y simplificada HADRIANOS SEBASTOS, respalda la visión de que en esta ciudad se acuñaron sólo emisiones de cierta entidad en los primerísimos meses de su reinado, continuando aún la estela productiva de Trajano. Adriano renunció además a la égida jupiterina en sus bustos antioquenos, motivo anterior favorito de Trajano y señal inequívoca de que no se consideraba por entonces como protegido por Júpiter. ${ }^{57}$ La negativa tanto a adoptar

52. En otoño de este año 117, aunque fue rechazado por parte de Adriano, Birley, 1997, p. 135.

53. RIC II. Hadrian, nos. 3 a-e; HA, Hadr. 6, 3-4; Birley, 2004b, p. 112.

54. Birley, 2004b, p. 127 y nos. 1 y 2, 414; RIC II. Hadrian, nos. 41, 543-545, 551.

55. HA, Hadr. 5,3; 9, 1; Eutr., VIII 6, 2, que es el único autor antiguo en mencionar una provincia de Asiria; Front., Princ. Hist. 1, 1; Birley, 2004b, pp. 108-109.

56. Butcher, 2004, p. 38.

57. Butcher, 2004, p. 92.

ARYS, 16, 2018 [63-103] ISSN 1575-166X 
durante diez largos años el título trajáneo de PATER PATRIAE ${ }^{58}$ cuanto su decisión de no retener cualquier consulado más allá de un tercero reflejan también una gran inseguridad por parte de Adriano. ${ }^{59}$

Una vez no obstante que las acuñaciones del nuevo emperador comenzaron a adoptar un sello más personal en Roma entre los años 119 y 122, uno de los temas de difusión predominante fue el de la renovación, algo que se hizo patente en dos notables series de monedas áureas del año 121, conmemorando una el saeculum aureum y otra el dies natalis de la capital. ${ }^{60}$ Este mismo año también se ocupó Adriano de la restauración del pomoerium, o límite religioso de la capital, que tan ocupado iba a traer al nuevo emperador durante su primera gira de viajes al tratar de identificarlo con las fronteras del imperio. ${ }^{61}$ En consonancia con esta política de legitimación imperatoria debe mencionarse además a la serie de áureos adriánea acuñada entre los años 119 y 122, en las que se muestra en el reverso a un Hércules desnudo, sentado y en posición frontal, con escudo, coraza y piel de león debajo del brazo izquierdo, además de con huso de hilar en la mano derecha, todo ello rodeado por la leyenda P M TR P COS III. ${ }^{62}$ Tanto por la inscripción del anverso, IMP CAESAR TRAIAN HADRIANVS AVG cuanto por el estilo del retrato (busto estilizado, con las mismas proporciones que el típico aplicado a Trajano), no hay duda de que esta serie fue emitida durante los años de la primera estancia de Adriano en Roma ${ }^{63}$ (Fig. 5). ${ }^{64}$

La indolente posición de Hércules en este tipo monetal, así como la representación de un huso de hilar en la mano derecha, no puede llevar no obstante a ninguna confusión acerca de la identificación exacta de esta particular advocación. Por asesinar a su amigo Ífito en un ataque de locura, Hércules había sido vendido como esclavo durante tres largos años a Ónfale, reina de Lidia. ${ }^{65}$ Ésta pronto alivió su suerte, haciéndole sin embargo su amante. Como consecuencia, y mientras se encontró a su servicio, Hércules se relajó, se volvió afeminado y se vistió con ropas y adornos típicos de mujeres, tejiendo además hilados. ${ }^{66}$ El Ara Máxima de Hercules Invictus,

58. Hasta finales del año 138, cuando adopta de nuevo tal título, Kienast, 2004, p. 129.

59. Birley, 2004b, p. 112; Beckmann, 2012, p. 410.

60. RIC II. Hadrian, 136, 144; Beckmann, 2012, p. 412; Bellen, 1997.

61. López Sánchez, 2007, pp. 61-72; Hekster, 2005: “(...) the famous fight between Cacus and Hercules, ending with the latter's victory and founding of the Ara Maxima and the Forum Boarium. In this story, then, a clear connection was laid down between the travelling deity and the city of Rome" (pp. 207-208).

62. COS III fue incorporado en las leyendas monetales en el año 119, RIC II. Hadrian, 347.

63. RIC II. Hadrian, pp. 347-357 (pp. 347-353, sin leyendas adicionales).

64. RIC II. Hadrian, no. 55.

65. Apoll, II 6, 1-3.

66. Prop., IV 9, 47-50. 
pues de este Hércules en concreto se trata en esta representación aúrea de Adriano, era un antiguo altar situado en el Foro Boario de Roma, en las proximidades del río Tíber. Fue el más antiguo centro de culto de Hércules en la Urbs, precedente del templo circular de Hercules Victor, atribuyendo la tradición romana a este sitio el lugar exacto en donde Hércules había matado a Caco y en donde Evandro había erigido posteriormente este templo. ${ }^{67}$ No se sabe nada acerca de la devoción de Adriano a Hercules Invictus en Roma durante sus primeros años de reinado. Sin embargo, sí que se conoce bien la que practicó aquí Cómodo a finales del siglo II, y en unas circunstancias personales muy semejantes a las vividas por Adriano décadas atrás. La vinculación especial de Cómodo con Hercules Invictus, también llamado Hercules Romanus, es así probablemente pertinente en la aclaración de la importancia de su representación en los comienzos del reinado de Adriano.

Como Adriano antes que él, Cómodo se había visto también impelido tras acceder al trono a abandonar las actividades militares de su predecesor Marco Aurelio en el frente danubiano. Y ello para acudir rápidamente a Roma con el objeto de afianzar su frágil posición en la púrpura. ${ }^{68}$ Como Adriano, y posiblemente incluso más que Adriano, Cómodo se entusiasmó igualmente en su devoción hacia Hércules durante una buena parte de su reinado. También, y de nuevo como en el caso de Adriano, multitud de monedas de Cómodo al comienzo de su reinado - hacia el año 190 - presentan un programa de renovación imperial: SAECULI TEMPORUM FELIC(itas). ${ }^{69}$ Precisamente en este contexto de renovación del imperio a partir de Roma, Cómodo se vistió igualmente con ropas femeninas en el templo de Hercules Invictus, no haciéndolo sin embargo como resultado de deseos personales o desviación de ningún tipo, ${ }^{70}$ sino por querer asumir mejor el papel de Hercules Romanus o Hercules Invictus, el semidiós del Ara Máxima romana. ${ }^{71}$ Las túnicas de Cómodo fueron así en realidad unas vestimentas sacerdotales derivadas del Este y unas a través de las cuales

67. Liv., I 7, 10-11; IX, 29, 9; Dionys., I 40, 6; Fest., 237; Serv., Aen. VIII. 269-271; Hekster, 2002, p. 108.

68. Hekster, 2002, pp. 42-49.

69. Hekster, 2002, p. 107.

70. Erkell, 1993, pp. 39-43.

71. Roma es la única ciudad que es proclamada INVICTA en las series monetales romanas de cualquier época antigua, Metlich, 2004, pp. 112-118, pl. IX-X frente a otras como Ravena, Ticino o Cartago que sólo son FELIX, Metlich, 2004, pp. 48-53. Por definición, una ciudad no puede ser vencedora (Victrix) sobre un enemigo, pero sí que puede se inexpugnable y no ser conquistada (Invicta). El título de Invicta asociada a Roma puede haber sido la razón por la cual el título de Invictus estuvo ligado tan estrechamente con la ciduad de Roma. Emperadores como Probo (278-282) y otros tardorromanos pudieron haber hecho suyo este título al considerarse salvaguardas de la inviolabilidad de Roma y de sus murallas, construidas por Aureliano. 
el nuevo emperador pudo identificarse con el Hercules Romanus del Ara Máxima. La razón de esta premura y preocupación de Cómodo por identificarse con Hercules Romanus resulto ser no obstante muy importante: gracias a tal asociación el emperador pudo mantener mágicamente el statu quo de las fronteras romanas más allá de la Ur$b s .{ }^{72}$ A este respecto, no se sabe si Adriano cumplió en algún momento entre los años 119 y 121 con alguno de los actos que sí que se sabe que ejecutó Cómodo en el Ara Máxima. Lo que sí que puede afirmarse es que Adriano quiso vincularse con Hercules Romanus contemporáneamente a su primer tour expedicionario. Su propósito puede inferirse entonces que fue el de propiciar religiosamente la fijación de las fronteras del imperio, verdadero objetivo de su primera gira viajera por Occidente.

Hercules Invictus puede considerarse de esta manera como el Hercules Romanus al cual se asocia el pomoerium que Adriano intentó ajustar en las fronteras externas a partir del año 121. Un pomoerium que ciertamente se encontraba protegido frente al mundo bárbaro de las fronteras externas por parte de Júpiter (Fig. 6), ${ }^{73}$ pero que se identificaba en su delimitación romana con Hercules Invictus. Adriano honró en todo caso a Hercules Invictus en su relación con la fijación de los confines del imperio en unas emisiones argénteas de los años 125-128. En ellas Hercules Romanus adopta además la tipología característica de Roma sentada en asociación con el epígrafe $A d$ ventus de los años $118^{74}$ y $134 .^{75}$

Aunque ciertamente no se inscribe el epígrafe Adventus en las emisiones adrianeas de estos años 125-128, Hércules se encuentra representado en la misma posición majestuosa (Fig. 7), adoptada por la personificación de Roma que acoge la entrada (adventus) del emperador en la Urbs (Fig. 8). ${ }^{76}$ De esta manera, y durante los años 125 y 128, los grabadores de la ceca de Roma parecen haber querido indicar a través de estas series hercúleas la entrada en la ciudad de Roma de Adriano, pero sin recurrir no obstante a la tipología propia del Adventus, adoptada sólo durante los años 118 y 134. La razón de tal variación puede no haber sido otra que la de evitar señalar una llegada formal y definitiva de Adriano a la capital. Ciertamente, mediante la adopción

72. Hekster, 2002, pp. 124-125.

73. RIC II. Hadrian, no. 63 (Júpiter en posición frontal), no. 64 (Júpiter sentado a la izquierda), como la Fig. 6.

74. RIC II. Hadrian, no. 554.

75. RIC II. Hadrian, nos. 224-227.

76. Las posiciones a izquierda y a derecha en los reversos monetales son importantes. El tipo de Profectio (partida en campaña) se orienta a la derecha y el de Adventus (regreso de la campaña) a la izquierda. Ver también a este respecto los comentarios sobre las leyendas EXPED(ITIO) AUG(USTA) Y EXPEDITIO AUGUSTI de Rosenberg, 1992, p. 98. 
de la serie Hercules Invictus con huso de hilar o con victoria con corona, ${ }^{77}$ se había señalado la disposición a conformar un oikoumene civilizado. Por su parte, las series de pseudo-adventus del período 125-128 sólo indican un respiro en la magna tarea de organización imperial de Adriano.

\section{Hercules Gaditanus: ¿Gades, puerto de aVituallamiento para ACTUAR EN MAURITANIA?}

Al mismo tiempo en que se acuñaban los áureos en honor de Hercules Invictus / Romanus, se emitieron también otras serie monetales de carácter hercúleo en Roma. No se hicieron sin embargo en honor de un Hércules romano, sino de Hercules Gaditanus, advocación que gozaba de los más altos honores en el sur de España desde hacía muchos siglos. ${ }^{78} \mathrm{~A}$ este respecto, el áureo más significativo y explícito de los seis diferentes que se considera que poseen una vinculación directa con esta advocación hispana es aquel que lleva la leyenda HERC(ules) GADIT(anus) en el campo de su reverso. ${ }^{79}$ Representa a la figura del semidiós estante, con su tradicional clava y con lo que parece ser una manzana (¿de las Hespérides?). ${ }^{80} \mathrm{~A}$ sus pies, se figura a Océano reclinado y a una proa (¿de guerra?) a la izquierda (Fig. 9). En los restantes áureos de este grupo se figura a Hércules con lo que parecen ser dos sacerdotisas, o a Hércules en solitario (Fig. 10). ${ }^{81}$ Aparece en todo caso el héroe en el interior de un templo diástilo o tetrástilo, siempre acompañado por Océano y/o por la proa de una nave a sus pies. ${ }^{82} \mathrm{La}$ inclusión de la figura de Hércules dentro de un templo, o, en el caso de no hacerlo, la inscripción de una leyenda aclaratoria alusiva a él, parece señalar que los grabadores monetales romanos quisieron identificar muy claramente la advocación hercúlea gaditana. Una advocación que con toda probabilidad se asimilaba con la estatua del santuario de Hércules-Melkart en la isla de Sancti Petri. ${ }^{83}$

Es posible que estos áureos fuesen acuñados en Roma coincidiendo con una probable visita de Adriano a la ciudad de Gades a principios del año 123, razón por la cual el templo de Hércules-Melkart pudo haber recibido además el derecho a recibir herencias, privilegio que compartiría desde entonces con otros pocos santuarios

77. RIC II. Hadrian, nos. 148 (con Victoria con guirnalda) y 149 (con huso de hilar).

78. López Castro, 1998, pp. 93-108.

79. RIC II. Hadrian, no. 125.

80. RIC II. Hadrian, nos. 59-61.

81. RIC II. Hadrian, nos. 56-58.

82. Barry, 2011, pp. 22-23.

83. Mierse, 2004, pp. 545-575.

ARYS, 16, 2018 [63-103] ISSN 1575-166x 
mediterráneos. ${ }^{84}$ Sin embargo, y a falta de documentos literarios o epigráficos más precisos provenientes de la Historia Augusta, la hipótesis de una visita de Adriano al templo y a la ciudad de Gades tras su estancia en Tarraco no pasa de ser una mera hipótesis. ${ }^{85}$ Ninguna fuente asimila tampoco el privilegio mencionado a una hipotética concesión a la ciudad del título honorífico de "metrópolis", de forma similar a como se hizo por entonces con ciertas ciudades orientales, tales como Sidón o Tiro. De lo que no puede caber ninguna duda, sin embargo, es de que, en los seis tipos áureos que de una manera u otra hacen alusión a Hercules Gaditanus, el elemento marítimo es insistentemente repetido. Y lo es además de una forma característica, que en otras amonedaciones imperiales se utiliza siempre para enfatizar la existencia de un puerto naval moderno, capaz de albergar flotas de entidad. Este es el caso, v. gr., del famoso sestercio de Nerón que muestra el recientemente reacondicionado puerto de Ostia (Fig. 11a). ${ }^{86}$ La representación que se hace en esta acuñación de unas disposiciones portuarias concretas coincide de hecho con la manera en cómo se ilustra en el áureo HERC GADIT al puerto de Gades. Para señalar la bondad de las instalaciones ostiense y gaditana los grabadores figuran además varias proas de naves y a dos templos, o aedículos de templos, con sus respectivas divinidades protectoras dentro (Fig. 11b).

Puede comentarse en relación con los cuadros monetales representativos de puertos, galeras u otros aspectos marinos dominantes que no pocas series acuñadas durante el reinado de Trajano en Sidón o en Dora figuran en sus flanes la inscripción navarchis o "Señora de la Flota". Asimismo, en otras series monetales de Laodicea ad Mare y de Trípolis se utiliza también el mismo término en tiempos de Adriano. No está claro qué quiere significar exactamente este término, pero su asociación con acuñaciones llamadas "semi-autónomas" en el Líbano, esto es, con emisiones de carácter no totalmente independiente o cívico y sí mediatizadas por el poder imperial, desaconsejan seguir la interpretación dada al término por parte de C. G. Starr. Esto es, que las ciudades que recibieron el título de navarchis asumieron parte de los gastos marítimos de transporte en el contexto de las guerras partas y judías de Trajano y Adriano. ${ }^{87}$ Al contrario, y como lo defiende M. Sartre, es más correcto interpretar que las ciudades que recibieron este título distintivo en la costa libanesa facilitaron

84. Ulp., Regl. 22, 6; Garzón Blanco, 1988, pp. 257-265; Alföldy, 2014.

85. Birley, 2004b, pp. 197-199.

86. La presencia de la proa de guerra en estos áureos no es anodina y está en relación con la calidad del puerto de la ciudad de Gades, capaz de albergar y avituallar a una flota imperial. Así, al menos, se hacen representar las ciudades fenicias a las que distintos emperadores concedieron el título de navarchis (“Señora de las naves"), Burrell, 2004, p. 252.

87. Starr, 1960, p. 187. 
en momentos de necesidad servicios a las distintas flotas imperiales que recabaron en sus puertos. ${ }^{88}$ Por ejemplo, la flota de Miseno, responsable última de las principales actividades militares en el Mediterráneo occidental, destacó también en el Mediteráneo oriental con ocasión de las guerras partas y judías de Trajano y Adriano. ${ }^{89}$ Así, es a su presencia en varias ciudades libanesas a la que parece que hace referencia la inscripción de navarchis.

Es cierto a este respecto que las actividades militares en la Mauritania Tingitana desde el sur de España en el siglo II están bien documentadas durante los reinados de Antonino Pío, entre los años 143 y 149 y de Marco Aurelio, durante los años 171173 y 177, pero no para época de Adriano. Fue entonces cuando con seguridad el sur de Hispania y la Tingitana atrajeron la intervención de destacamentos importantes de las flotas imperiales italianas de Miseno y de Ravena. ${ }^{90}$ Poco antes del reinado de Adriano, es verdad que está atestiguada la existencia de un prefecto de la Ora Maritima y de las cohortes I y II. L. Cornelius Celsus en torno a la costa próxima a Tarraco, ${ }^{91}$ aunque también es cierto que nada permite pensar en la existencia de una flotilla permanente en la costa gaditana a principios del siglo II. Y sin embargo, y a pesar de todo, la rápida y concisa sucesión de acontecimientos que narra la HA con ocasión de los últimos momentos de la presencia de Adriano en la península ibérica, antes de su vuelta a Roma, ${ }^{92}$ sólo se entiende si se acepta que el emperador utilizó los servicios de un destacamento de la flota imperial de Miseno. ${ }^{93}$ Una Gades que actuase en Hispania a principios de la segunda década del siglo II como "Señora de la Flota" (navarchis), salvo en el título, no implica necesariamente que existiesen actividades militares de entidad en la Mauritania Tinigitana en el año 123 y a partir de esta ciudad hispana, aunque tampoco deba descartarse tal hipótesis. ${ }^{94} \mathrm{El}$ énfasis puesto en el puerto gaditano y en el culto a Hércules-Melkart en la serie de áureos referida, lo que sí que parece significar en todo caso es una remodelación de las instalaciones navie-

88. Sartre, 2005, p. 185.

89. Starr, 1960, p. 188.

90. HA, Ant. Pius. 5, 4; Starr, 1960, pp. 120, 123, 189 y n. 43.

91. Ruiz de Arbulo, 2011-2012, pp. 560-562.

92. HA, Hadr. 12, 8, Birley, 2004b, pp. 198-199.

93. Garzetti, 1974, p. 390; Ver también López Sánchez, 2012b para el desplazamiento de destacamentos de la flota de Miseno en Hispania en épocas anteriores al reinado de Adriano.

94. Birley, 2004a, cree firmemente en una intervención de Adriano en la Mauritania Tingitana en el año 123: "Al final de su visita a España parece posible que el emperador viajara más allá del estrecho hasta Mauritania. En cualquier caso, algo sucedió allí en este momento que con probabilidad pudo haber requerido su participación personal: según la Historia Augusta 'ahogó una sublevación de los moros, por lo cual se ganó del Senado un agradecimiento oficial (supplicationes)'” (p. 61). 
ras de la ciudad. Y ello en previsión de una reestructuración del círculo del Estrecho en relación con una Mauritania Tingitana pacificada. El que la Mauritania Caesarensis fuese visitada posteriormente por Adriano en exclusividad quizás se debió a que las labores previas en el puerto de Cádiz hicieron innecesario volver a la Mauritania Tingitana. ${ }^{95}$

\section{Zeus (Iovis) Olympius: Adriano y su Panhelenio asiático}

A finales del año 128, y tras haber inspeccionado y pacificado todas las regiones sensibles de Occidente, Adriano llegó a Atenas como si de un nuevo Hércules se tratase. Eran éstos los comienzos de la segunda de sus grandes giras y durante los seis meses en los que se detuvo en la ciudad, el emperador comenzó la construcción de un Olympeion, un gran templo en honor de Zeus Olympius. Sin embargo, ya en marzo del año 129 Adriano partió hacia Éfeso ${ }^{96}$ y algunos detalles de su estancia aquí los proporciona una inscripción de ese año en la que se caracteriza al emperador no sólo a través de su nuevo título Olympius, sino también en tanto que "fundador y salvador" de la ciudad. ${ }^{97}$ "Fundador" es un epíteto que casa bien con Hércules, pero Salvador (Soter) es un apelativo que acompaña tradicionalmente a Zeus y a sus protegidos en Oriente. Parece razonable así inferir que Adriano quiso asimilarse a partir del año 129 con Júpiter / Zeus, el dios más poderoso del estado romano y también del oikumene. ${ }^{98}$ Es cierto a este respecto que el amor que Adriano profesaba por Éfeso era bien conocido en la antigüedad, pero la aclamación allí del emperador en tanto que Olympius añadió una nueva dimensión a su vínculo de afecto. Así, y aunque la adoración de Iovis Olympius (en latín arcaico, y no en griego) no fuese nueva en Éfeso, pues el dios había dispuesto de un templo en la ciudad desde al menos el reinado de Domiciano, la llegada de Adriano puede considerarse bajo el prisma de una verdadera epifanía jupiterina. Se acuñaron además en honor de Iovis Olympius numerosos tetradacmas y es imposible no ver en estas monedas una expresión de los sentimientos y proyectos que Adriano poseía acerca de su nueva fase de gobierno imperial. La representación en estos tetradacmas de Júpiter entronizado sosteniendo una pequeña estatua de Ar-

95. Las mejoras de los puertos de algunas ciudades favorecidas por Adriano, como Éfeso en el año 129, fueron profusamente celebradas durante su reinado (Metcalf, 1980, p. 23); Para la Mauritania Caesarensis, Birley, 2004b, pp. 262-275.

96. Birley, 2004b, pp. 283-284.

97. Metcalf, 1980, p. 23.

98. Plin., Pan. 80, 4; 88, 8. 
temisa en su mano ejemplifica como nada la estrecha relación que Adriano quería con Iovis Olympius en Éfeso (Fig. 12). ${ }^{99}$

En Esmirna, ciudad igualmente visitada por el emperador en el año 129, se promocionó también a Zeus Akraios, "el dios de la altura", una divinidad muy similar al Iovis Olympius de Éfeso. Zeus Akraios poseía un gran templo en una colina cercana a la ciudad, ahora conocida como Deirman-Tepe y rivalizaba en tamaño con el templo de Zeus que Adriano pretendía construir en Atenas. En todo caso, hasta tal punto son similares las composiciones tipológicas de las acuñaciones de Esmirna y las de Éfeso a partir del año 129 que W.E. Metcalf duda en la adscripción de algunos de los cistóforos acuñados en Esmirna a Zeus Akraios o a Iovis Olympius (Fig. 13). ${ }^{100}$ $\mathrm{Y}$ estas similitudes de las divinidades de importantes ciudades con respecto Júpiter y con ocasión de la gira de Adriano por la región no deben limitarse únicamente a Éfeso o a Esmirna, pues también en Cízico o en Pérgamo se dieron casos semejantes. En Pérgamo, por ejemplo, una ciudad por la cual no consta que pasase por entonces Adriano, pero que sin duda se vio afectada por el entusiasmo jupiterino de la región, un templo con neocorato en la ciudad aparece como dedicado a Zeus Helios precisamente en el año 129. ${ }^{101}$

En contradicción sólo aparente con lo expuesto hasta aquí, es cierto que no puede negarse que no pocas ciudades de la costa jonia se negaron a formar parte de la iniciativa panhelénica de Adriano durante los años 131-132. Una excesiva profusión de títulos inflamaba las querellas interurbanas tradicionales en la región, razón por la cual Adriano no obtuvo siempre la adhesión deseada a sus planes panhelénicos. Sin embargo, puede afirmarse que aquellos apoyos que consiguió Adriano lo fueron de verdad, erigiéndose en precioso testimonio de ello las acuñaciones de cistóforos jupiterinos en Asia Menor.

\section{Sandan de Tarso y Zeus en Cilicia: Adriano, rey helenístico}

Al sur de las ciudades helenófonas de Asia Menor se encontraba Antioquía en el Orontes, la antigua capital seleúcida, ciudad en la que Adriano instaló una gran estatua sentada de Zeus sosteniendo la esfera celeste. ${ }^{102}$ Antioquía, como otras grandes urbes griegas de Asia Menor era devota desde tiempos helenísticos de un Zeus par-

99. Metcalf, 1980, pp. 23-24; RPC III, nos 1340-1341.

100. El Zeus Akraios de Esmirna sostiene la estatuilla de Artemisa de Éfeso en su mano derecha, Metcalf, 1980, pp. 37-38; RPC III, no 1358.

101. Guerber, 2012, 235.

102. Malalas, 11. 278, 14; Boatwright, 2000, pp. 137-138. 
ticular, Zeus Casius, así como de su rayo, dos cultos que se supone que habían sido establecidos por Seleuco Nicátor cuando éste fundó la ciudad. ${ }^{103}$ Entre los lugares de Asia anteriormente visitados y Antioquía se situaban no obstante otras regiones de variada importancia, entre ellas Capadocia, que fue transitada con seguridad por Adriano en el año 129, según indican la Historia Augusta y varios testimonios monetales. ${ }^{104} \mathrm{~A}$ diferencia sin embargo de Asia, las regiones más al interior de Anatolia y limítrofes o identificadas con Cilicia, poseían un fuerte sustrato medizante y oriental en el siglo II, el cual había sido potenciado y revivido desde los tiempos finales de la era seleúcida. ${ }^{105}$ En todo caso, y tras haber recorrido Capadocia, la Historia Augusta no especifica en dónde recibió exactamente el emperador a una delegación de varios príncipes orientales. ${ }^{106}$ Pudo haber sido en Satala, en Samosata o en Melitene, pero nada se sabe a ciencia cierta y pudo haber sucedido en cualquiera de estos lugares, $o$ en otro muy diferente también. La ciudad de Tarso, como gran parte de Cilicia, había sido recorrida por Adriano a comienzos de su reinado, por lo que una estancia de carácter más prolongado durante su segunda gira, aunque materia cuestionable, no es del todo imposible.

Estuviese o no físicamente Adriano en Tarso, lo cierto es que durante su reinado se acuñó en Cilicia un volumen muy considerable de emisiones de plata, especialmente en las ciudades de Calycadnus (137-138), Tarso (después del año 129), Aegeae (117-118, y 128-129 a 133-134), y Mopsus (117-118, 121-122). Lo más interesante de esta producción cilicia es que M. Amandry la interpreta como coordinada de una forma u otra por la capital del koinon, y por encima de ella por la autoridad imperial. ${ }^{107}$ Además, la razón última por la cual se multiplicaron exponencialmente estas acuñaciones en el koinon de Cilicia presidido por Tarso puede que no haya sido otra que las operaciones militares dirigidas por Sextus Julius Severus para terminar con la rebelión de Shim'on ben Koseba en Judea. ${ }^{108}$ Ciertamente, Antioquía se había encargado en el pasado inmediato de gestionar las operaciones militares que desde esta ciudad se adentraban hacia el norte de Siria y Mesopotamia, pero ahora el nuevo bellum Iudaicum ${ }^{109}$ parecía exigir otras rutas de avituallamiento marítimas. Por esta misma razón las acuñaciones de Sidón y Tiro habían tenido ya su importancia du-

103. Houghton, Lorber y Hoover, 2008, p. 213.

104. Birley, 2004b, pp. 287-288.

105. Canepa, 2017, pp. 200-222.

106. HA, Hadr.13, 8-9.

107. Butcher, 2004, p. 92.

108. Amandry, 2012, p. 398.

109. Hier., Chron. 283F; Halfman, 1986, pp. 209-211. 
rante el reinado de Trajano, y en conexión con las revueltas hebreas en Alejandría y en Chipre. En la tercera década del siglo II, no obstante, parece que las ciudades de Cilicia se consideraron más idóneas que las fenicias del Líbano como bases logísticas para las flotas imperiales que actuaron en Judea. En consecuencia se trasladó el grueso de la producción de plata en Oriente desde Antioquía a Cilicia. ${ }^{110}$

En lo que respecta a Tarso, la capital del koinon de Cilicia, no puede saberse si el culto de Adriano, el templo vinculado al koinon o su neokoria, aspectos todos muy importantes que se aprecian en las monedas de esta ceca a partir del año 128/129, se debieron o no a unas concesiones especiales de este emperador en el contexto de su segunda gira por Oriente. Tampoco constituyen estas tres distinciones prueba incontestable por sí mismas de su presencia física en la ciudad. Lo único que puede demostrarse para la ciudad de Tarso a partir del año 129 es que ésta desarrolló unas actividades acuñadoras más importantes que las de la otrora todopoderosa ceca de Antioquía. ${ }^{111}$ En relación con este particular puede señalarse además que entre los notables tipos monetales promocionados en Tarso a partir del año 129 destaca el que representa al dios Sandán en su reverso y conjuntamente con la leyenda TAPCE $\Omega N$ МНТРОПО $\Lambda$ Е $\Omega$ C. ${ }^{112}$ Sandán, Sandon o Sandas era un antiguo dios de Anatolia asociado con la guerra y el clima, conocido en el área de Tarso desde la época de apogeo de los hititas. Sandán en su forma hurrito-hitita era Teshub, un dios de las tormentas de la montaña y sus pies nunca tocaban tierra. Se representa en este tipo monetal como estante sobre un león con cuernos caminando a la derecha, vestido con una larga túnica, con una alta tiara sobre su cabeza, con una espada y un carcaj sobre su hombro izquierdo. También levanta su mano derecha al mismo tiempo que sostiene en ella una corona y un bipennis (Fig. 14). ${ }^{113}$

Sandán era una deidad muy similar a Hadad o a Zeus Hadados, muy popular éste en la región de Doliche, siendo por lo demás Iupiter Dolichenus el nombre dado por los romanos a la manifestación romana del dios de la tormenta del Cercano Oriente, especialmente difundido también por oficiales del ejército desde la región de Siria y Cilicia hasta Germania e incluso Britania. ${ }^{114}$ En todo caso, y aunque Sandán se

110. Aegeae fue la última de las tres ciudades del koinon cilicio en recibir el neocorato, tras Tarso y Anazarbos. En tiempos de Adriano la importancia de sus acuñaciones parece estar más en relación con la actividad de su puerto que con cuestiones puramente cúlticas (Haymann, 2014, pp. 143-186; Burrell, 2004, p. 230).

111. Burrell, 2004, p. 213.

112. Burrell, 2004, pp. 212-213.

113. Prieur y Prieur, 2000, nos. 767-769; RPC III, nos 3266-3268.

114. Collar, 2013, pp. 79-145. 
había asimilado por esta época con Herakles, co-fundador de Tarso conjuntamente con Apolo Lykeios-Mitra y Perseo según Antípatro de Tesalónica, sus atributos y características le asemejaban más con Zeus (Fig. 15). ${ }^{115}$

La visibilidad de Sandán en las series monetales grecorromanas había sido muy variable en el pasado, dependiendo siempre de la necesidad de apoyo de distintos soberanos en la región. El dios había sido por primera vez favorecido en las amonedaciones a nombre de Alejandro Balas a mediados del siglo II a.C. (150-146 a.C.), pues este usurpador había necesitado en cierto momento del apoyo de Tarso y de su chora en el contexto de sus luchas por el poder en Siria. ${ }^{116} \mathrm{La}$ devoción mostrada por Adriano a Sandán en Tarso, además de a otras divinidades similares como la situada en lo alto del Monte Argaios (Argaeus en latín), parecen indicar así que el emperador quiso ligarse a un Júpiter regional, tonante y guerrero. ${ }^{117}$ Un Júpiter ante todo árbitro de los acontecimientos y sostén de la legitimidad del gobierno. Un Júpiter que había sido favorecido por anteriores reyes selúcidas con problemas en la región y que ahora indica el interés de Adriano por su afirmación soberana en el Levante.

\section{IUpiter Victor en Aelia Capitolina y en Roma: Adriano, señor DEL OIKUMENE}

Tras su visita a Egipto, y después del ahogamiento de Antinóo en el Nilo el 30 de octubre del año 130, Adriano volvió sobre sus pasos a través de Siria y Asia Menor hasta llegar de nuevo a Atenas, ciudad que visitó por tercera vez y en la cual pasó el invierno del año 131-132. ${ }^{118}$ Muchos fueron los favores que, una vez más, prodigó el emperador a esta ciudad y que son descritos por Pausanias y por Casio Dión. ${ }^{119}$ Además de las embajadas recibidas y los rescriptos enviados, los juegos presididos y otras actividades desempeñadas, el acontecimiento sin duda más importante de esta tercera visita fue la dedicación formal del santuario de Zeus Olympius con su estatua crisoelefantina. ${ }^{120}$ Aunque no existe descripción conocida de la inauguración del Panhelenio, programado desde hacía tiempo, ésta debió producirse al mismo tiempo en que se realizó la dedicación formal del templo. Se dijo entonces que el Panhelenio debería reunirse cada cuatro años para celebrar los Panhellenia, ade-

115. Prieur y Prieur, 2000, no 770; RPC III, nos 3269-3270.

116. Houghton, Lorber y Hoover, 2008, pp. 211, 218.

117. Birley, 2004b, p. 288; Sydenham, 1978.

118. Birley, 2004b, pp. 334-341.

119. Paus., I. 3, 2; Cass. Dio, LXIX. 16, 1-2.

120. Paus., I. 18. 6; I. 24, 7; Cass. Dio 69. 16, 1; HA, Hadr. 13, 6. 
más de otros juegos olímpicos y panateneos. ${ }^{121}$ De esta manera, Atenas se convirtió efectivamente en una nueva capital imperial para Adriano, no sólo del mundo helenófono, sino también de todo el oikoumene al este de Italia. Unos posibles terceros ritos mistéricos pudieron también haber reafirmado a Adriano en su compromiso con su proyecto filoheleno. ${ }^{122}$

No obstante, en este contexto de renovación filohelénica de Adriano se produjo la revuelta de Bar-Kokhba en Judea que tanto condicionaría los acontecimientos vistos anteriormente en Cilicia. El historiador romano Dión Casio atribuye las alteraciones a la decisión de Adriano de construir un templo a Júpiter (Zeus Olympius) en el lugar preciso del Gran Templo venerado por los judíos de Jerusalén (Hierosolyma o Yerushalayim), renombrando además a la ciudad como Aelia Capitolina y ligando así su propio nombre al de Júpiter. ${ }^{123}$ Aunque las fuentes judías asignen una mayor prioridad a los decretos que prohibían la circuncisión por parte del emperador, ${ }^{124} \mathrm{el}$ respeto del sábado y las leyes de pureza en la familia, esta tradición no es excluyente, sino más bien solidaria, con la causa enunciada por Dión Casio. ${ }^{125}$ En todo caso, la construcción planificada en honor de Júpiter Capitolino en el Monte del Templo de Jerusalén se reconoce universalmente por parte de la crítica moderna como la verdadera causa del levantamiento liderado por Bar-Kokhba. ${ }^{126} \mathrm{Y}$ existe a este respecto testimonio en las acuñaciones de la ciudad refundada de cómo se rindió culto a $I u$ piter Capitolinus dentro de un templo dístilo con Júpiter sentado y acompañado por Minerva y Juno (Fig. 16). ${ }^{127} \mathrm{~A}$ los tres años de que se iniciara la rebelión, las luchas culminaron además con la victoria romana en el verano del año 135. Después de perder Jerusalén, Bar-Kokhba y los restos de su ejército se retiraron a la fortaleza de Betar, que fue sitiada y finalmente tomada.

No obstante, y a pesar del total triunfo romano, A. Birley indica acertadamente que "la celebración de la victoria en las monedas imperiales fue notoriamente comedida e indirecta en comparación con otras guerras anteriores". ${ }^{128} \mathrm{Y}$ es que, aunque Adriano aceptó en el año 134-135 la que sólo fue su segunda aclamación en tanto

121. Birley, 2004b, pp. 337-339.

122. Birley, 2004b, p. 334.

123. Cass. Dio, LXIX 12, 1-2; Birley, 2004b, pp. 232-233.

124. Para Adriano ésta era una costumbre bárbara, HA, Hadr. 14.2.

125. Eliav, 1997, pp. 125-144.

126. Mantel, 1968, pp. 224-242, 274-296; Golan, 1986, pp. 226-239.

127. Ecker y Cotton Hannah, 2012, pp. 492-493; RPC III, no 3963.

128. Birley, 2004b, p. 350. 
que imperator (IMP II) tras la victoria judaica, ${ }^{129}$ tal titulatura no fue reflejada por los grabadores monetales romanos en ninguna de sus amonedaciones. Se ha intentado seguir a este respecto el triunfo de Adriano sobre los judíos en representaciones monetales de la diosa Victoria, sentada o estante y rodeada por la leyenda VICTORIA $\mathrm{AVG},{ }^{130}$ y con seguridad dichos rastreos pueden ser considerados como correctos. ${ }^{131}$ Los áureos con Júpiter entronizado a la izquierda, sosteniendo a Victoria con guirnalda y con leyenda IOVI VICTORI, ${ }^{132}$ los cuales se considera que fueron acuñados entre los años 134 y 138 (Fig. 17) han escapado no obstante a la crítica numismática e histórica. Deben sin embargo considerarse también como ligados a esa "indirecta" celebración de Adriano por su victoria judaica. Otras series de sestercios en honor de Jupiter Custos - IOVI CUSTODI - parecen haberse acuñado igualmente en solidaridad con estas series aúreas. ${ }^{133}$

Si la causa de la guerra judía contra Adriano había sido la construcción del templo a Zeus Olympius en Jerusalén, es lógico considerar que en las acuñaciones destinadas a conmemorar el aplastamiento de la rebelión se potenciase al dios cuyo levantamiento del templo había provocado la revuelta. Este razonamiento explicaría suficientemente las leyendas de IUPITER VICTOR y IOVI CUSTODI. Sin embargo IUPITER VICTOR y IOVI CUSTODI no sólo son conmemorados en las acuñaciones de Adriano por haber sido reparado el honor de Júpiter en Judea. Júpiter era también desde el año 129 el cosmocrator que unía a todo el imperio bajo la égida de Adriano, por lo que su exaltación en el año 135 en Roma celebra la unificación triunfante del imperio. De esta manera, el recorrido realizado por Adriano desde los años 119-122 en los que Hercules Invictus había sido el principal custodio de las fronteras del imperio, y hasta el año 135, resulta coherente. Adriano conmemora a IUPITER VICTOR y no acuña en memoria de una IUDAEA CAPTA, como hizo Vespasiano, porque no se encuentra interesado en mostrar la fijación de unos territorios y fronteras con anterioridad ya establecidos (años 121-126). A la más grave contestación a su proyecto panhelénico en Oriente Adriano responde así con la exaltación del dios supremo de Roma y de todo el oikumene. La "comedida" e "indirecta" celebración del año 135

129. Kienast, 2004, p. 130.

130. RIC II. Hadrian, nos. 281-286, y también, sin la leyenda VICTORIA AVG, pero con la representación de Victoria, nos. 344 y 345 . Todas las series son de denarios, salvo el no. 281, que es un quinario.

131. Birley, 2004b, p. 362.

132. RIC II. Hadrian, no. 251, la acuñación áurea con leyenda IOVI CONSERVATORI, no. 250, puede tener idéntico significado.

133. RIC II. Hadrian, nos. 763, 815. 
puede haber estado de esta manera más relacionada con el gobierno triunfante de Júpiter Capitolino en todo el oikumene que con la victoria judía en exclusividad. El modelo hérculeo-jupiterino iniciado por el emperador en el año 121 se consideraba por fin concluído en el año 135.

\section{Conclusiones}

La solidaridad existente en el mundo greco-romano entre Hércules y Júpiter fue explotada durante siglos. Júpiter era el árbitro de los dioses y consecuentemente el más importante de todos ellos. Por su parte, el héroe y semidivino Hércules era el mejor de todos los hombres: viajero, fundador y civilizador además de héroe esforzado, famoso vencedor en sus doce tareas. Júpiter era sin discusión el más importante de los dos, pero Hércules preparaba con su esfuerzo su gobierno en el oikumene.

La Macedonia de Filipo II y Alejandro III parece haber sido la primera entidad política de entidad en haber estructurado de forma coherente la dualidad hercúleojupiterina como un programa de gobierno complementario y sucesivo en el tiempo. Naturalmente, Herakles se había constituido desde antiguo en el ancestro de la casa real macedonia argéada y Zeus era también desde siempre el máximo dios del panteón griego, razones ambas por las cuales tal simbiosis puede parecer suficientemente natural y por tanto carente de significación especial. Sin embargo, los calculados juegos y complementariedades establecidos entre estas asimilaciones soberanas no parece que hayan sido consecuencia del azar ni para Filipo II ni para Alejandro III. De hecho, en el desarrollo imperial y territorial de Macedonia desde mediados del siglo IV a.C. puede apreciarse el terreno abonado para el desarrollo de dos fases de gobierno diferenciadas: una primera fundamentalmente hercúlea, militar y dedicada a la estabilización de las fronteras en un territorio variado e inestable y otra jupiterina, universalista y más gubernativa, centrada esencialmente en la administración de un territorio ya pacificado. Esta construcción ideológica y cultista, muy práctica también en el fondo, se encuentra muy bien establecida en el imperio romano de los augustos y césares de mediados del siglo IV d.C, aunque fue también practicada por otros sistemas colegiales imperiales en el siglo precedente, fundamentalmente, pero no únicamente, por parte de los emperadores hérculeo-jupiterinos Maximiano y Diocleciano.

El modelo ideológico imperial romano basado en Júpiter y en Hércules pudo haber comenzado no obstante bastante antes del siglo III. Lo habría iniciado ya Trajano en el siglo II d.C., aunque parece que quien lo desarrolló de verdad fue Adriano. A este respecto, las series monetales imperiales y cívicas de Adriano, sin ser tan ricas como las posteriores antoninas o severas, desarrollan sin embargo un programa ideológico complejo. Y es que, al contrario que sus predecesores en la púrpura romana, 
el filoheleno Adriano parece que quiso gobernar sobre un imperio por primera vez considerado como realmente ecuménico. Sobre este mundo quiso además Adriano ejercer como inspector, como árbitro y como emperador cosmocrator. Es por esta razón por la que O. Hekster denomina a este emperador como "antitradicional" en relación con sus predecesores. ${ }^{134}$ En realidad, Adriano parece haber buscado unos fundamentos ideológicos más helenos y menos latinos para su reinado, al menos en parte. Esta es la razón última de que estructurase su carrera de gobierno imperial en torno a una identificación de su persona con Hércules primero y con Júpiter después, tal y como también lo hicieron anteriormente otros reyes helenísticos y después lo harían no pocos emperadores romanos.

De la lectura de las series monetales expuestas en este artículo puede deducirse en todo caso que Adriano pretendió identificarse preferentemente con Hércules entre los años 119 y 126, esto es, tras su llegada a Roma desde Antioquía y hasta la conclusión de su primera gran gira de viajes. Y con Júpiter más tarde, entre el año 128, a partir de sus segundos ritos de Eleusis y hasta el año 135, con ocasión de la feliz conclusión del bellum Iudaicum cuando volvió por tercera y última vez a Roma. Puede defenderse igualmente que durante su primera etapa de gobierno, desempeñada fundamentalmente en Occidente, Adriano quiso comportarse en tanto que un pacator terrarum hercúleo. Y que durante una segunda fase imperatoria, pretendió hacerlo como un rector caeli, vinculándose entonces más a Júpiter. Y a la ciudad de Atenas, tanto como a la de Roma.

134. Hekster, 2005, p. 208. 


\section{IMÁGENES}
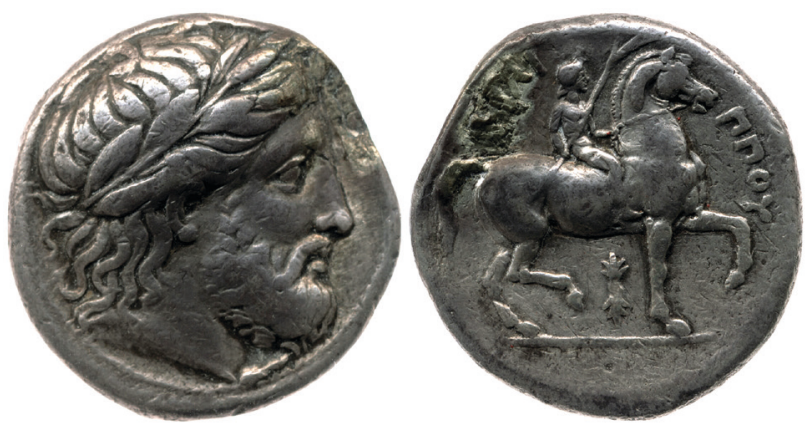

Fig.1. Tetradacma, Pella, Macedonia, 359-336 a.C. (circa). Busto barbado y laureado de Zeus a la derecha / ФІ АІППОҮ, Joven jinete desnudo a la derecha, 14.12 grs. $12 \mathrm{~h}$. Museum number 1918,0204.100. The Trustees of the British Museum.
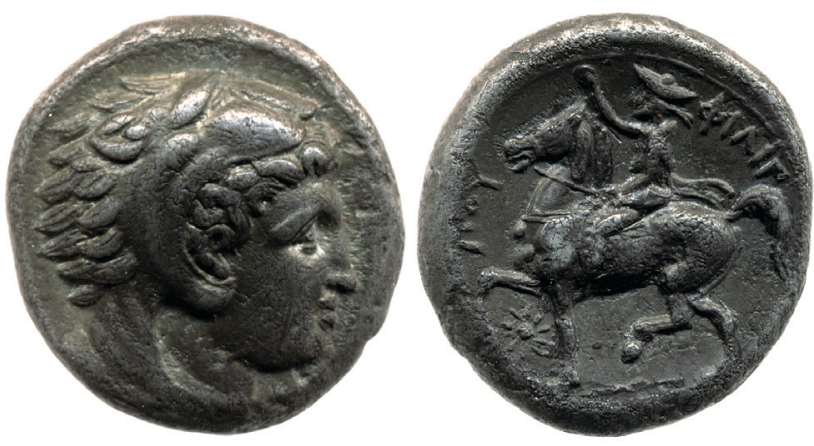

Fig. 2. Didracma, Pella, Macedonia. 359-336 a .C. (circa). Busto imberbe de Herakles a la derecha vistiendo leonté / ФІАІППОҮ, Jinete con petaso y clámide a la izquierda. 6.95 grs. 19 mm., 1 h. Museum number 1919, 0911.7. The Trustees of the British Museum. 

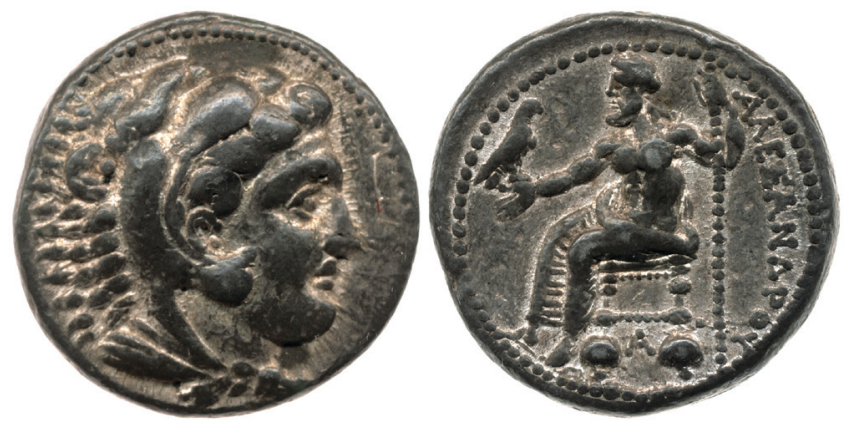

Fig. 3. Tetradracma de Alejandro Magno. Tarso 333-323 a.C. (circa). Busto del joven Herakles con leonté a la derecha / A $\Lambda$ E $\Xi A N \triangle P O Y$, Zeus sentado sosteniendo águila y cetro. 17.1 grs. 6 h. Museum number 1912,0905.17. The Trustees of the British Museum.
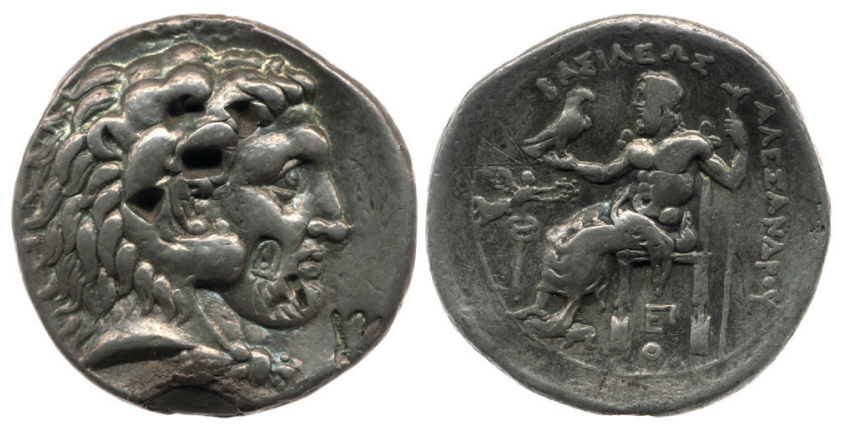

Fig. 4. Tetradacma póstumo de Alejandro Magno. Tarso, 323-317 a.C. (circa). Busto del joven Herakles con leonté a la derecha / BA $\Sigma I \Lambda E \Omega \Sigma$ A $\Lambda$ E $E A N \triangle P O Y$, Zeus sentado sosteniendo águila y cetro. Niké con corona y caduceo en el campo. 17.01 grs. $12 \mathrm{~h}$. Museum number 1880,0603.16. The Trustees of the British Museum. 

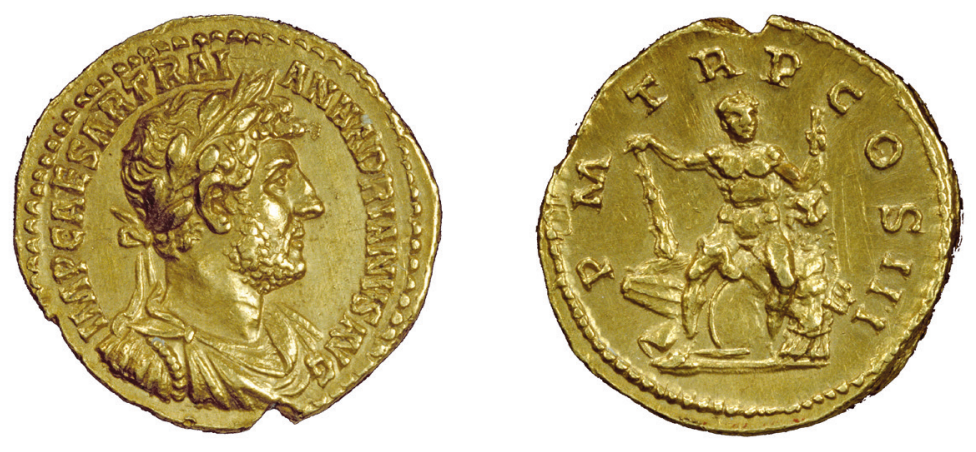

Fig. 5. Áureo. Roma. 119-122 d.C. IMP CAESAR TRAIAN HADRIANVS AVG III, busto de Adriano, laureado, con paludamentum y con coraza a la derecha / P M TR P COS, Hércules desnudo y sentado frontalmente sosteniendo clava y huso de hilar. 7.13 grs. 19 mm. 6 h. Museum number R.8047. The Trustess of the British Museum.
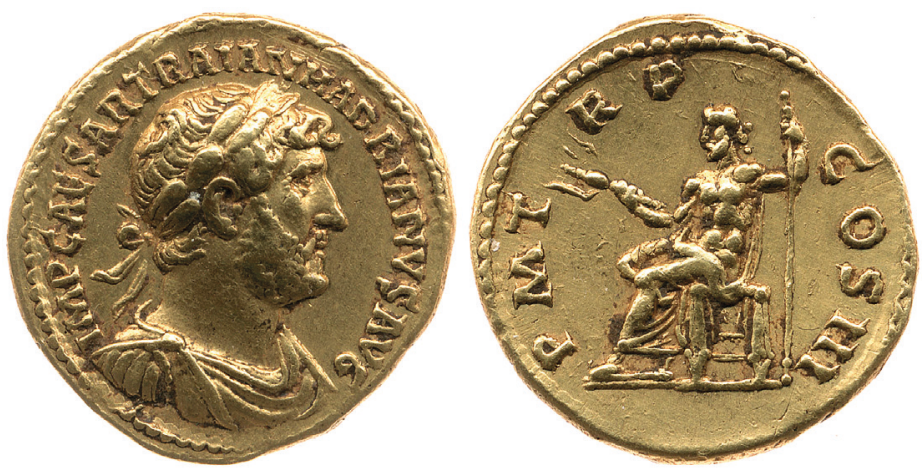

Fig. 6. Áureo. Roma. 119-122 d.C. IMP CAESAR TRAIAN HADRIANVS AVG III, busto de Adriano, laureado, con paludamentum y con coraza a la derecha / P M TR P COS, Júpiter sentado a la izquierda, sosteniendo haz de rayos y cetro. 7.29 grs. 6 h. Museum number R.8050. The Trustess of the British Museum. 

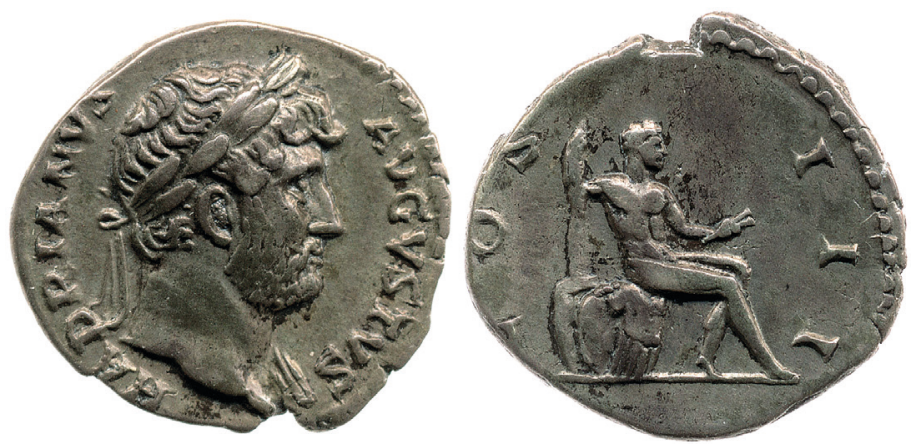

Fig. 7. Denario. Roma. 125-128 d.C. HADRIANVS AVGVSTVS, busto de Adriano laureado a la derecha, con paludamentum en su hombro izquierdo / COS III, Hércules desnudo, sentado sobre una coraza a la derecha, sosteniendo clava en su mano derecha y huso de hilar en la izquierda, 3.38 grs, $6 \mathrm{~h}$. Museum number 1911,0414.102. The Trustess of The British Museum.
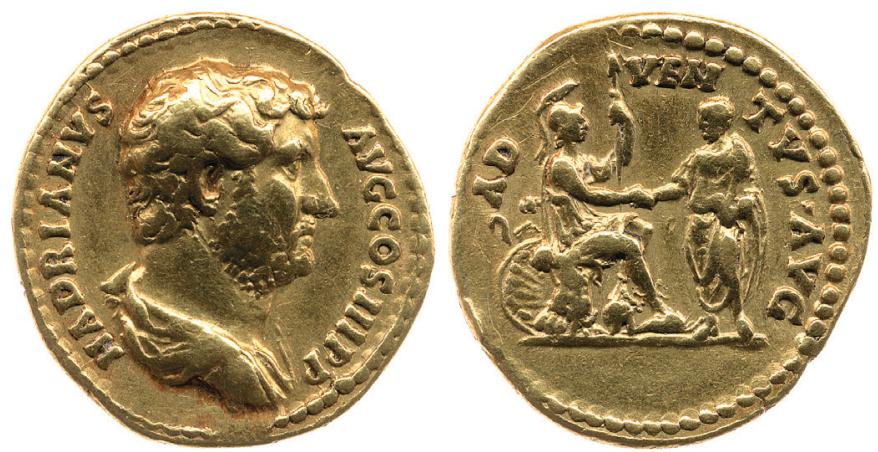

Fig. 8. Áureo. Roma, 134-138, d.C. HADRIANVS AVG COS III P P, busto de Adriano, con paludamentum y con coraza a la derecha / ADVENTVS AVG, Roma sentada a la derecha sobre coraza y armas, sosteniendo lanza en mano izquierda y estrechando mano derecha con Adriano, estante enfrente. 7.15 grs. $6 \mathrm{~h}$. Museum number 1907,0501.146. The Trustees of the British Museum. 

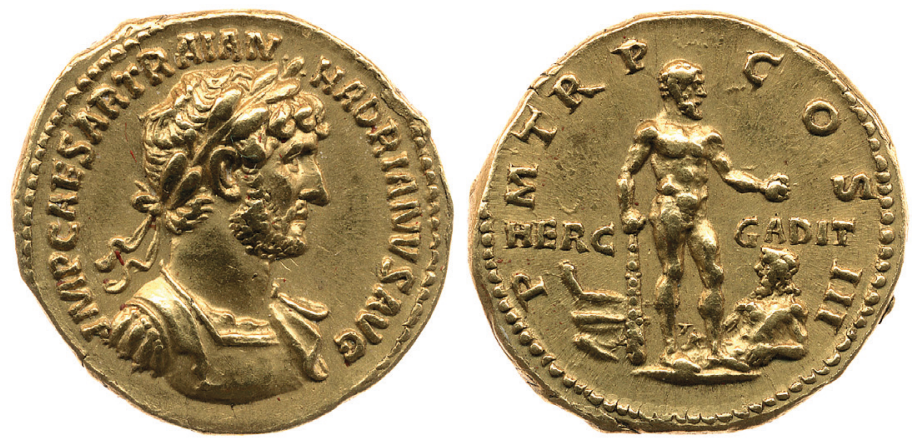

Fig. 9. Áureo. Roma. 119-122 d.C. IMP CAESAR TRAIAN HADRIANVS AVG, busto de Adriano, laureado y con coraza a la derecha / P M TR P COS III, Hércules estante a la derecha, apoyando brazo sobre clava y sosteniendo manzana en mano izquierda. A la izquierda proa de nave, Oceanus reclinado a la derecha, 7.27 grs. 6 h. Museum number 1864,1128.269. The Trustees of the British Museum.
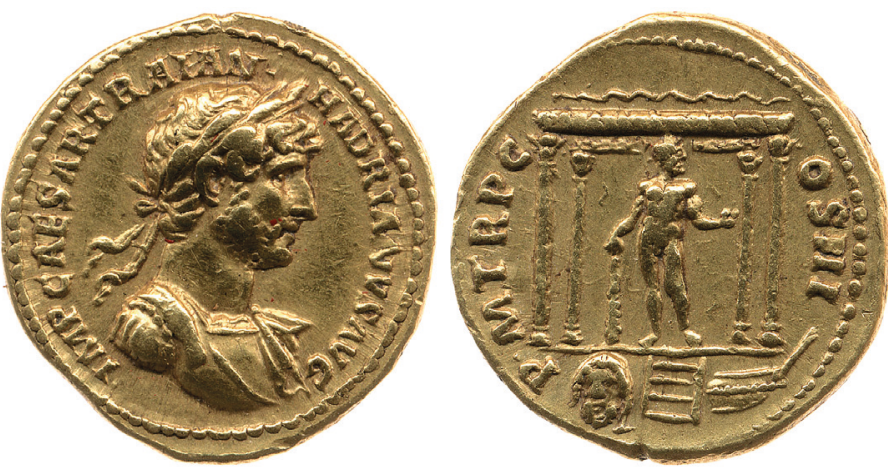

Fig. 10. Áureo. Roma. 119-122 d.C. IMP CAESAR TRAIAN HADRIANVS AVG, busto de Adriano, laureado, con paludamentum y con coraza a la derecha / P M TR P COS III, Hércules, estante de frente, busto a la derecha dentro de templo tetrástilo, sosteniendo clava y manzana $(\dot{i}$ ?), abajo, busto frontal y proa a la derecha. Museum number $1844,1008.147$. The Trustees of the British Museum. 

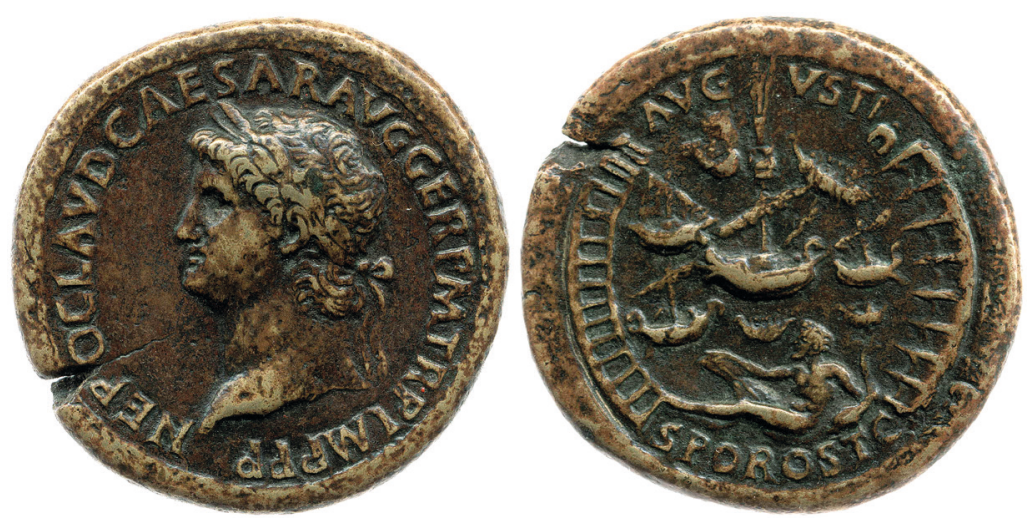

Fig. 11a. Sestercio. Roma. 64 d.C. NERO CLAVD CAESAR AVG GER P M TR P IMP P P, busto de Nerón laureado a la izquierda / AVGVSTI S POR OST C, panorama a vista de pájaro del puerto de Ostia, con naves y almacenes. Arriba, faro con edículo y estatua de Neptuno. Abajo, figura reclinada del Tíber, sosteniendo timón y delfín, 26.73 grs. 6 h. Museum number R.3615. The Trustees of the British Museum.

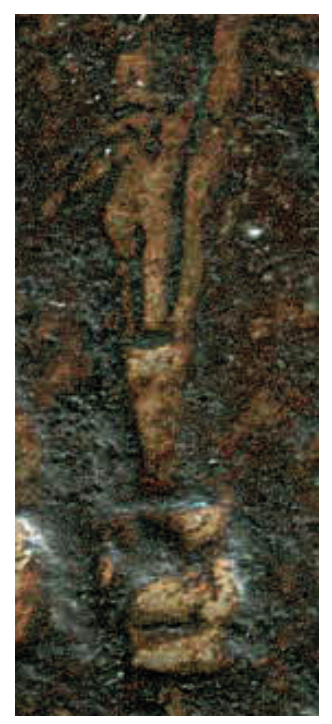

Fig. 11 b. Detalle del edículo con estatua de Neptuno, sosteniendo cetro en la mano izquierda. 

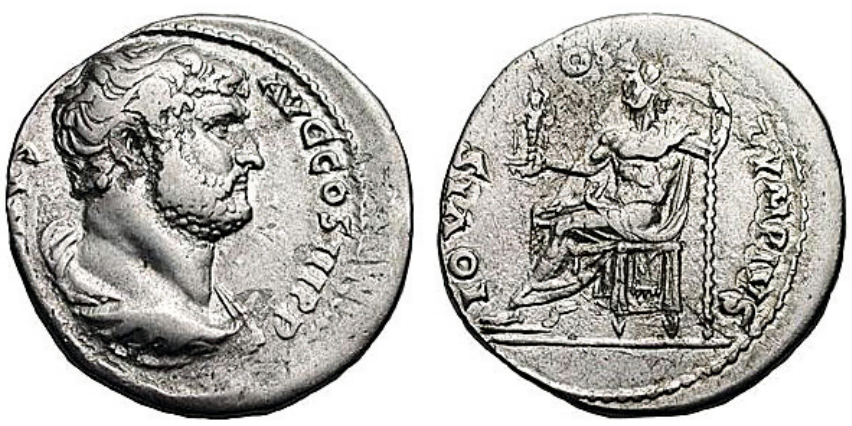

Fig. 12. Adriano. Tetradracma cistofórico de plata, Éfeso, Jonia. Después de marzo del año 129 d.C., [HADRIA] NVS AVG COS III P P, busto de Adriano con paludamentum a la derecha / IOVIS OLVMPIVS, Júpiter sentado a la izquierda, sosteniendo estatuilla de Diana de Éfeso y cetro, 10.50 grs., Gemini, LLC, 11.01.2006, Auction II, lot 390.
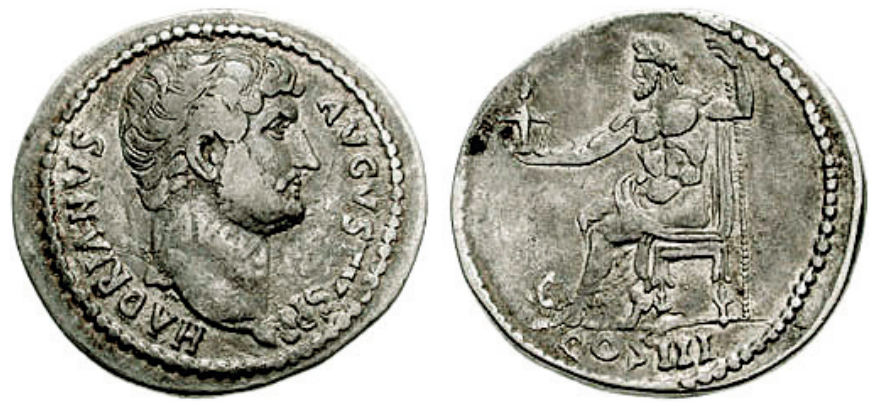

Fig. 13. Adriano. Tetradracma cistofórico de plata, Esmirna. Del, o después del, año 129 d.C. HADRIANVS AVGVSTVS PP, busto de Adriano a la derecha / Zeus sentado a la izquierda, con Diana Efesia sobre mano izquierda y cetro en la mano izquierda; águila a los pies. Classical Numismatic Group, Inc., Mail Bid Sale 66, Lot 1478. 

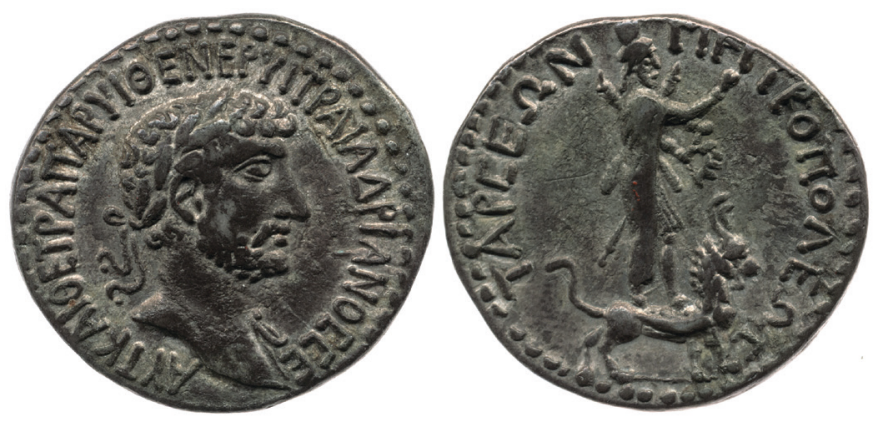

Fig. 14. Tetradacma. Tarso. Del, o después del, año 129 d.C.

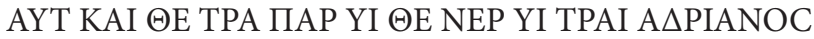
CE, busto laureado de Adriano a la derecha / TAPCE $\Omega N$ МНТРОПО $\Lambda$ Е $\Omega$, dios Sandán estante a la derecha, con carcaj, espada, bipennis y corona sobre león con cuernos. 9.4 grs. 12 h. Museum number 1897,0104.371. The Trustees of the British Museum.
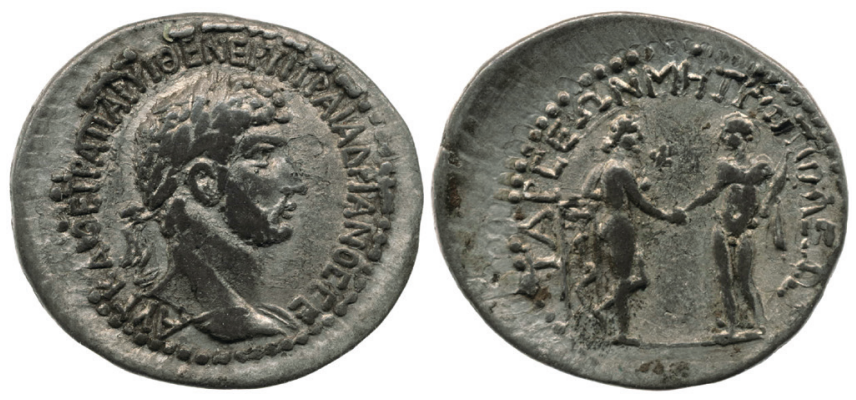

Fig. 15. Tetradacma. Tarso. Del, o después del, año 129 d.C.

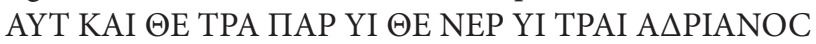
CE, busto laureado de Adriano a la derecha / TAPCE $\Omega N$ МНТРОПО $\Lambda$ ЕС, Apolo de pie a la izquierda, sosteniendo rama de laurel, dando la mano a Perseo, a la derecha con harpa. A la izquierda, trípode. Museum number 1970,0909.226. The Trustees of the British Museum. 

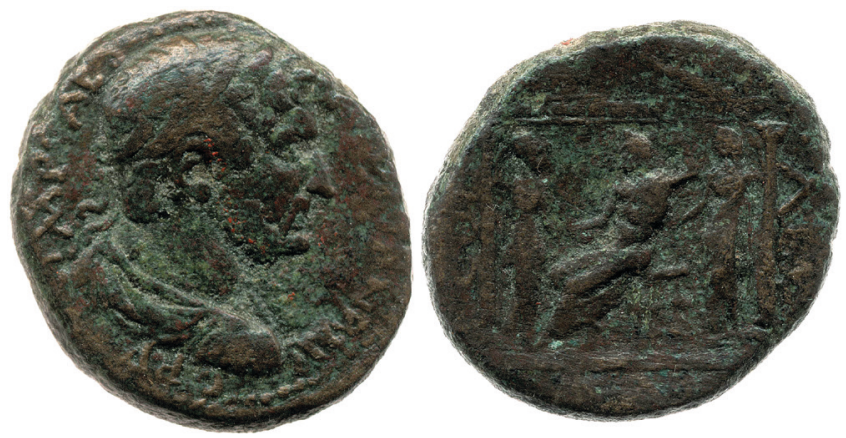

Fig. 16. Adriano. Bronce. 130-138 d.C. IMP CAES [TRAI HADR] IANO AVG PP, busto de Adriano laureado, con paludamentum y coraza a la derecha / COL AEL, templo de Júpiter Capitolino, mostrando dos columnas y frontón; dentro: en el centro, Júpiter sentado a la izquierda con cetro, a la izquierda, Minerva con casco y descansando sobre lanza, a la derecha Juno sosteniendo cetro a la izquierda, 16.81 grs, $12 \mathrm{~h}$. Museum number 1908,0110.1870. The Trustees of the British Museum.
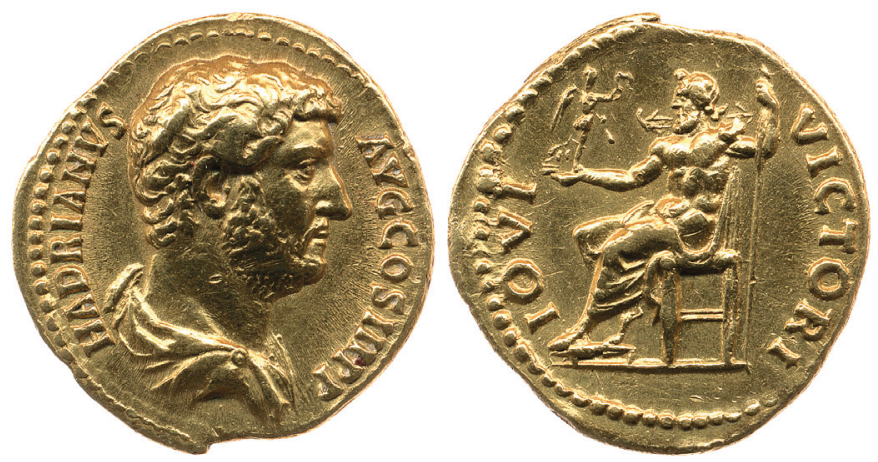

Fig. 17. Áureo, Roma 134-138 d.C. HADRIANVS AVG COS III P P, busto de Adriano, con paludamentum, a la derecha / IOVI VICTORI, Júpiter entronizado a la izquierda sosteniendo Victoria con guirnalda en la mano derecha y cetro en la izquierda. 7.04 grs. 6 h. Museum number 1933,0414.8. The Trustees of the British Museum. 


\section{Bibliografía}

Abdy, R., Besly, E., y López-Sánchez, F. (2010). The Gloucester hoard and other coin hoards of the Britannic Empire. Coin hoards from Roman Britain XIII. Wetteren: Moneta.

Alföldy, G. (2014). Hadrians Besuch in Tarraco (HA, H 12, 3-5). En Bertrand-Dagenbach y Chausson, 2014, pp. 11-29.

Alföldy, G. y Halfmann, H. (1973). El edetano M. Cornelius Nigrinus Curiatius Maternus: general de Domitiano y rival de Trajano. Valencia: Servicio de Investigación Prehistórica.

Alston, R. (2014). Aspects of Roman History 31 BC-AD 117. London y New York: Routledge, Taylor \& Francis Group.

Amandry, M. (2012). The Coinage of the Roman Provinces through Hadrian. En Metcalf, 2012, pp. 391-404.

Barry, F. (2011). The Mouth of Truth and the Forum Boarium: Oceanus, Hercules, and Hadrian. ABull, 93.1, pp. 7-37.

Bastien, P. (1972). Le monnayage de l'atelier de Lyon: Dioclétien et ses corégents avant la réforme monétaire (285-294). Wetteren: Éditions Numismatique Romaine.

Beckmann, M. (2012). Trajan and Hadrian. En Metcalf, 2012, pp. 405-422.

Bellen, H. (1997). Politik-Recht-Gesellschaft: studien zur Alten Geschichte. Stuttgart: Frank Steiner.

Bennett, J. $\left(2001^{2}\right)$. Trajan: Optimus Princeps, Bloomignton y Indianapolis: Indiana University Press.

Bertrand-Dagenbach, C. y Chausson, Fr. (eds.) (2014). Historiae Augustae Colloquium nanceiense. Atti dei Convegni sulla Historia Augusta XII. Munera 39. Bari: Edipuglia.

Birley, A.R. (1997). Hadrian and Greek senators. ZPE, 116, pp. 219-245.

Birley, A.R. (2004a). Los viajes de Adriano. En Cortés Copete y Muñiz Grijalvo, 2004, pp. 59-69.

Birley, A.R. (2004b). Adriano. La biografía de un emperador que cambió el curso de la historia. Barcelona: Gredos. 2a ed. trad. de José Luis Gil Aristu de Birley, A.R. (1997). Hadrian, The restlesss emperor. Londres.

BMC III = Mattingly, H. (1936). Coins of the Roman Empire in the British Museum. Vol.3, Nerva to Hadrian. Londres: Trustees of the British Museum.

Boatwright, M.T. (2000). Hadrian and the cities of the Roman Empire. Princeton y Oxford: Princeton University Press.

Boswortth, A.B. y Baynham, E.J. (2000). Alexander the Great in fact and Fiction. Oxford: Oxford University Press.

Brennan, T.C. (1998). The poets Julia Balbilla and Damo at the colossus of Memnon. The Classical World, 91.4, pp. 215-234.

Burnett, A. (2005). The imperial coinage of Egypt in the first century AD. En Duyrat y Picard, 2005, pp. 261-277.

Burrell, B. (2004). Neokoroi: Greek cities and Roman emperors. Leiden: Brill. 
Butcher, K. (2004). Coinage in Roman Syria: Northern Syria, 64 BC-AD 253. Londres: Royal Numismatic Society.

Canepa, M. (2017). Rival Images of Iranian Kingship and Persian Identity in Post-Achaemenid Western Asia. En Strootman y Versluys, 2017, pp. 200-222.

Casabonne, O. (2004). La Cilicie à l'époque achéménide. París: De Boccard.

Clinton, K. (1997). "Eleusis and the Romans: Late Republic to Marcus”, en M. C. Hoff y S. I. Rotroff (eds.), The Romanization of Athens. Proceedings of an International Conference held at Lincoln, Nebraska (April 1996), Oxford 161-172.

Clinton K. (1989). “Hadrian's contribution to the renaissance of Eleusis”, en S. Walker and A. Cameron (eds.) The Greek Renaissance in the Roman Empire, London, 56-68.

Collar, A. (2013). Religious networks in the Roman Empire: the spread of new ideas. Cambridge: Cambridge University Press.

Cortés Copete, J.M. y Muñiz Grijalvo, E. (eds.) (2004). Adriano Augusto. Sevilla: Fundación Jose María Lara.

Dahmen, K. (2007). The legend of Alexander the Great on Greek and Roman Coins. Londres y Nueva York: Routledge.

Duyrat, F. y Picard, O. (eds.) (2005). L'exception égyptienne? Production et échanges monétaires en Egypte hellénistique et romaine. Actes du colloque d'Alexandrie, 13-15 avril 2002. El Cairo: Institut français d'archéologie orientale.

Ecker, A. y Cotton Hannah, M. (2012). The Date of the Founding of Aelia Capitolina, s.v. Gitler, Haim. "Roman Coinages of Palestine". En Metcalf, 2012, pp. 492-493.

Eliav, Y.Z. (1997). Hadrian's actions in the Jerusalem Temple Mount according to Cassius Dio and Xiphilini Manus. Jewish Studies Quarterly, 4.2, pp. 125-144.

Elkins, N.T. y Krmnicek, St. (eds.) (2014). 'Art in the Round'. New Approaches to Ancient Coin Iconography. Rahden: VML, Verlag Marie Leidorf $\mathrm{GmbH}$.

Erkell, H.(1993). L'imperatore Commodo ed Ercole-Melcart. ORom, 19, pp. 39-43.

Flower, M. (2000). Alexander the Great and Panhellenism. En Bosworth y Baynham, 2000, pp. 96-135.

Fredricksmeyer, E.A. (1961). Alexander, Midas and the Oracle at Gordium. CPh, 56, pp. 160 168.

Fredricksmeyer, E.A. (1991). Alexander, Zeus Ammon and the Conquest of Asia.TAPhA, 121, pp. 199-214.

Fredricksmeyer, E.A. (2000). Alexander the Great and the Kingdom of Asia. En Bosworth $y$ Baynham, 2000, pp. 136-166.

Garzetti, A. (1974). From Tiberius to the Antonines. A History of the Roman Empire AD 14-192. London: Routledge. Translated form the Italian by J.R. Foster. First published as Garzetti, A. (1960). L'impero da Tiberio agli Antonini, Bologna: Cappelli.

Garzón Blanco, J.A. (1988). La propaganda imperial en las monedas de Hércules, 'Hercvles Gaditanvs' Minerva y 'Minerva Gaditana' emitidas desde Trajano, a Antonino Pío. Baetica, 11, pp. 257-265. 
Golan, D. (1986). Hadrian's Decision to Supplant 'Jerusalem' by 'Aelia Capitolina'. Historia, 35.2, pp. 226-239.

Gordillo Hervás, R. (2012). La construcción religiosa de la Hélade imperial: el Panhelenion. Florencia: Firenze University Press.

Guerber, É. (2012). Princes itinérants et gratifications impériales. Notes sur les voyages d'Hadrien en Asie. En Hostein y Lalanne, 2012, pp. 231-245.

Halfmann, H. (1986). Itinera Principum. Geschichte und Typologie der Kaiserreisen im römischen Reich. Stuttgart: F. Steiner Verlag Wiesbaden.

Haymann, F. (2014). The Hadrianic Silver Coinage of Aegeae (Cilicia). AJN, 26, pp. 143-186.

Hammond, N.G.L. y Walbank, F.W. (2003). Relations with the Greek States. En Worthington, 2003, pp. 81-89.

Hekster, O. (2002). Commodus: an emperor at the crossroads. Amsterdam: Gieben.

Hekster, O. (2005). Propagating power: Hercules as an example for second-century emperors. En Rawlings y Bowden (2005), pp. 205-221.

Hollard, D. (ed.) (2006). L'armée et la Monnaie, I. Société d'Études Numismatiques et Archéologiques. Paris: Séna.

Hostein, A. y Lalanne, S. (eds.) (2012). Les voyages des empereurs dans l'Orient romain: époques antonine et sévérienne. Paris: Errance.

Houghton, A., Lorber, C. y Hoover, O. (2008). Seleucid coins: a comprehensive catalogue. Pt. 2, v. 1. Seleucus IV through Antiochus XIII (introduction, maps and catalogue). Nueva York y Lancaster: American Numismatic Society y Association with the Classical Numismatic Group.

Kienast, D. $\left(2004^{4}\right)$. Römische Kaisertabelle: Grundzüge einer römischen Kaiserchronologie. Darmstadt: Wissenschaftliche Buchgesellschaft.

Kuhoff, W. (2001). Diokletian und die Epoche der Tetrarchie: das römische Reich zwischen Krisenbewältigung und Neuaufbau (284-313 n. Chr.). Frankfurt: Lang.

Levick, B. (1999). Vespasian. London y NewYork: Routledge.

López Castro, J.L. (1998). Familia, poder y culto a Melqart gaditano. ARYS, 1, pp. 93-108.

López Sánchez, F. 2006. La série légionnaire de Victorin et ses emblèmes ad hoc. En Hollard, 2006, pp. 37-49.

López Sánchez, F. (2007). Hadrien et la Vème cohorte prétorienne. RBN, 153, pp. 61-72.

López Sánchez, F. (ed.) (2012a). The Coin and the City in the Ancient and Early Medieval Worlds. BAR International Series 2402. Oxford: Archaeopress.

López Sánchez, F. (2012b). The Coinage of Carthago Nova and the Roman Fleet of Missenum: Imperial Triumphs and Local Deductiones. En López Sánchez, 2012a, pp. 73-90.

Mantel, H. 1968. The Causes of the Bar Kokba Revolt. Jewish Quarterly Review, 58.3-4, pp. 224-242, 274-296.

Metcalf, W.E. (1980). The cistophori of Hadrian. Nueva York: American Numismatic Society. Metcalf, W.E. (ed.) (2012). The Oxford handbook of Greek and Roman coinage. Oxford y Nueva York: Oxford University Press.

Metlich, A. (2004). The Coinage of Ostrogothic Italy. Londres: Spink. 
Mierse, W.E. (2004). The Architecture of the Lost Temple of Hercules Gaditanus and Its Levantine Associations. AJA, 108.4, pp. 545-575.

Nixon, C.E.V. y Rodgers, B.S. (1994). In praise of later Roman emperors: the Panegyrici Latini. Berkeley y Oxford: University of California Press.

Oliver, J.H. (1950). Hadrian's Precedent, the Alleged Initiation of Philip II. AJP, 71.3, pp. 295299.

Price, M. (1991). The coinage in the name of Alexander the Great and Philip Arrhidaeus: a British Museum catalogue, I. Londres: Swiss Numismatic Society in assocition with British Museum.

Prieur, M. y Prieur, K. (2000). A type corpus of the Syro-Phoenician tetradrachms and their fractions from $57 \mathrm{BC}$ to $A D$ 253. Lancaster, Pa: Classical Numismatic Group.

RIC II = Mattingly, H. y Sydenham, E.A. (1926). Roman Imperial Coinage. Vol. 2, Vespasian to Hadrian. Londres: Spink \& Son.

RIC VI = Sutherland, C.H.V.(1967). The Roman Imperial Coinage. Volume 6. From Diocletian's Reform (A.D. 294) to the Death of Maximian (A.D. 313). Londres: Spink \& Son.

Rawlings, L. y Bowden, H. (2005). Herakles and Hercules. Exploring a Graeco-Roman Divinity. Swansea: Classical Press of Wales.

Rees, R. (2002). Layers of loyalty in Latin panegyric, AD 289-307. Oxford: Oxford University Press.

Rees, R. (2005). The emperor's new names: Diocletian Jovius and Maximian Herculius. En Rawlings y Bowden, 2005, pp. 223-239.

RPC II = Burnett, A., Amandry, M. y Carradice, I. (1999). Roman Provincial Coinage. Vol. II: From Vespasian to Domitian (AD 69-96). London y Paris: Spink and Sons.

RPC III = Roman Provincial Coinage Online. Volume III. Nerva to Hadrian (AD 96-138). https://rpc.ashmus.ox.ac.uk/search/advanced/?v=3\&search=Search.

Rosenberg, V. (1992). Bella et expeditiones. Die antike Terminologie der Kriege Roms. Stuttgart: Franz Steiner.

Ruiz de Arbulo, J. (2011-2012). La dedicatoria a Mars Campester del centurión T. Aurelius Decimus y el campus de la guarnición imperial de Tarraco en el siglo II d.C. Algunas reflexiones sobre la topografía militar de la capital provincial. CuPAUAM, 37-38, pp. 553-569.

San Vicente, J.I. (2002). Moneda y propaganda política: de Diocleciano a Constantino. Vitoria: Universidad del País Vasco.

Sartre, M. (2005). The Middle East under Rome. Cambridge, Mass. y London: Belknap Press of Harvard University Press.

Spaeth, B.S. (1996). The Roman goddess Ceres. Austin: University of Texas Press.

Starr, C.G. $\left(1960^{2}\right)$. The Roman imperial navy, 31 B.C.-A.D. 324. Cambridge: W. Heffer.

Steinbock, B. (2014). Coin Types and Latin Panegyrics as Means of Imperial Communication. En Elkins y Krmnicek, 2014, pp. 51-67.

Strootman, R. y Versluys, M.J. (eds.) (2017). Persianisms in Antiquity, Colloquium, $2014 \mathrm{Ne-}$ derlands Instituut in Turkije. Stuttgart: Franz Steiner Verlag. 
Thonemann, P. (2015). The Hellenistic world: using coins as sources. Cambridge: Cambridge University Press.

Troxell, H.A. (1997). Studies in the Macedonian. Coinage of Alexander the Great. Numismatic Studies 21. Nueva York: American Numismatic Society.

Wallace-Hadrill, A. (1986). Image and authority in the coinage of Augustus. JRS, 76, pp. 66-87.

Williams, C.A. (2010). Roman homosexuality. Nueva York y Oxford: Oxford University Press. Worthington, I. (2003). Alexander the Great. A reader. London y New York: Routledge. 